\title{
Test Report for the INL Sunlution Photovoltaic Module Ground Clip Test
}

\author{
Larry Zirker
}

Jason Bush

April 2012

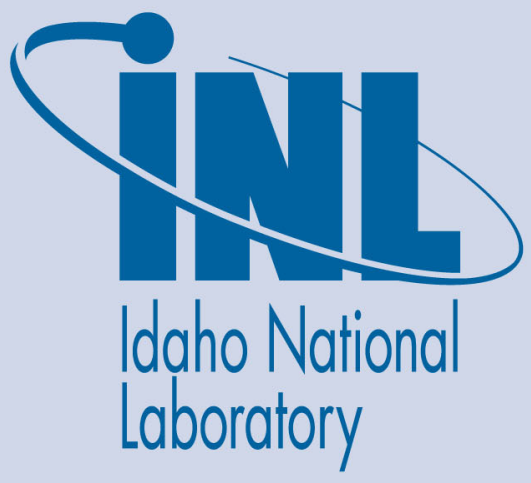

The INL is a U.S. Department of Energy National Laboratory operated by Battelle Energy Alliance 


\section{DISCLAIMER}

This information was prepared as an account of work sponsored by an agency of the U.S. Government. Neither the U.S. Government nor any agency thereof, nor any of their employees, makes any warranty, expressed or implied, or assumes any legal liability or responsibility for the accuracy, completeness, or usefulness, of any information, apparatus, product, or process disclosed, or represents that its use would not infringe privately owned rights. References herein to any specific commercial product, process, or service by trade name, trade mark, manufacturer, or otherwise, does not necessarily constitute or imply its endorsement, recommendation, or favoring by the U.S. Government or any agency thereof. The views and opinions of authors expressed herein do not necessarily state or reflect those of the U.S. Government or any agency thereof. 
INL/EXT-12-25588

\title{
Test Report for the INL Sunlution Photovoltaic Module Ground Clip Test
}

\author{
Larry Zirker \\ Jason Bush
}

April 2012

Idaho National Laboratory Idaho Falls, Idaho 83415

http://www.inl.gov

\author{
Prepared for the \\ U.S. Department of Energy \\ Office of Nuclear Energy \\ Under DOE Idaho Operations Office \\ Contract DE-AC07-05ID14517
}





\section{CONTENTS}

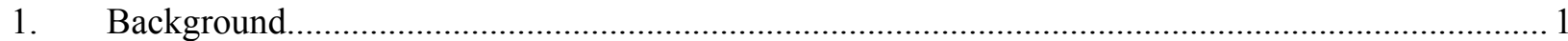

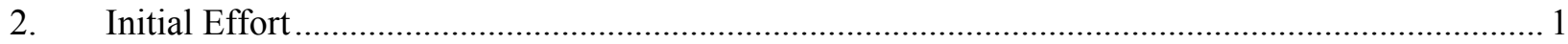

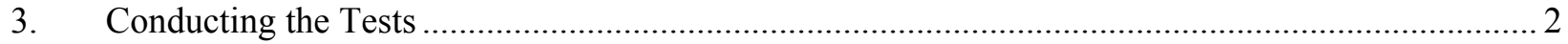

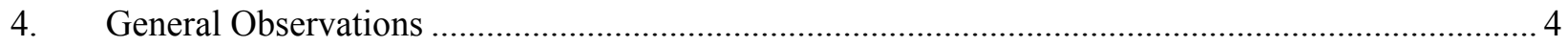

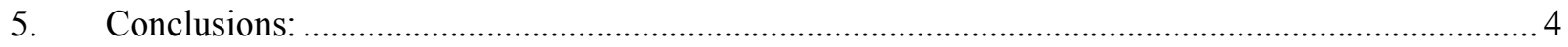

Appendix A "Preliminary” INL Proof of Concept Test Plan ................................................................. 5

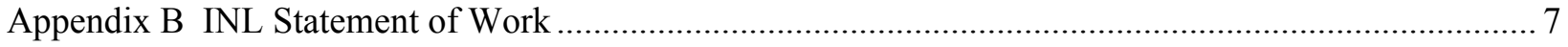

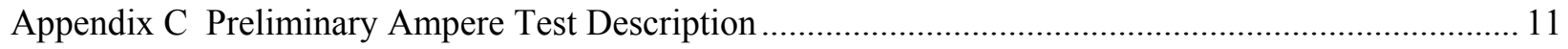

Appendix D Field Change to LI 1305-07-IRC, Battery and Capacitor Testing ................................... 15

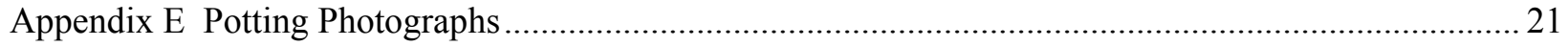

Appendix F Ampere Test Photographs, Technician Comments, Graphs, and Data .............................. 23

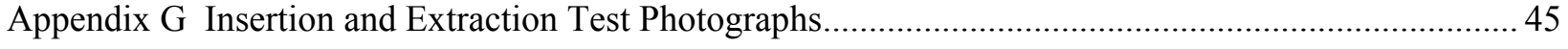

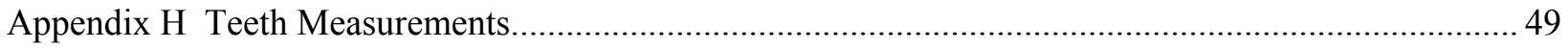

\section{FIGURES}

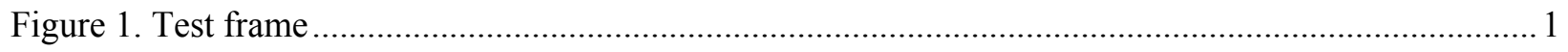

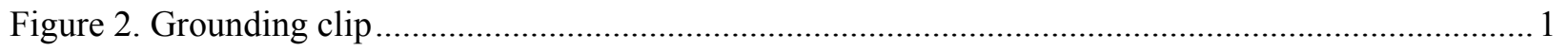

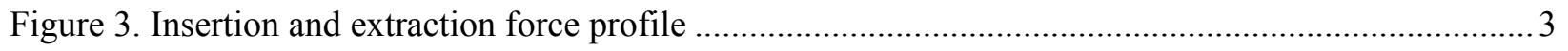

Figure 4. Scratch depth of 275 micrometers or 0.011 -inch................................................................. 4

Figure 5. solitary scratch on one side of insertion/extraction test...................................................... 4

\section{TABLES}

Table 1. Section from UL 467 standard on testing 3 


\section{Test Report for the INL Sunlution Photovoltaic Module Ground Clip Test}

\section{Background}

In April 2012, Sunlution, LLC asked the Idaho National Laboratory (INL) for a small proof test of their proposed solar panel grounding clip. Since it was a renewable energy item, Stephanie Cook, of INL Technology Deployment, asked Jason Bush, of the INL Biofuels and Renewable Energy Technology group, to lead the effort. Jason asked Larry Zirker to assist with this effort because of his prior work experience in testing items. Stephanie called a meeting with the team, which included a conference call with Jeff Roth, President of Sunlution, LLC, of Boise, Idaho. The project was discussed and questions were asked regarding the deliverables requested. Some of testing could not be accomplished within the requested the 40-hour limitation (i.e., the thermal cycling of the clip), but an agreement was reach on what could be done, and the project was started. To conduct the test, Mr. Roth sent the INL three complete sets of clips and frames. Figure 1 shows the test frame that represents a solar panel frame; Figure 2 shows the clip. The small number of clips (three) presented a significant problem in accurately defining the functionality of the clip, but with the limited time and funding available, this number was deemed satisfactory.

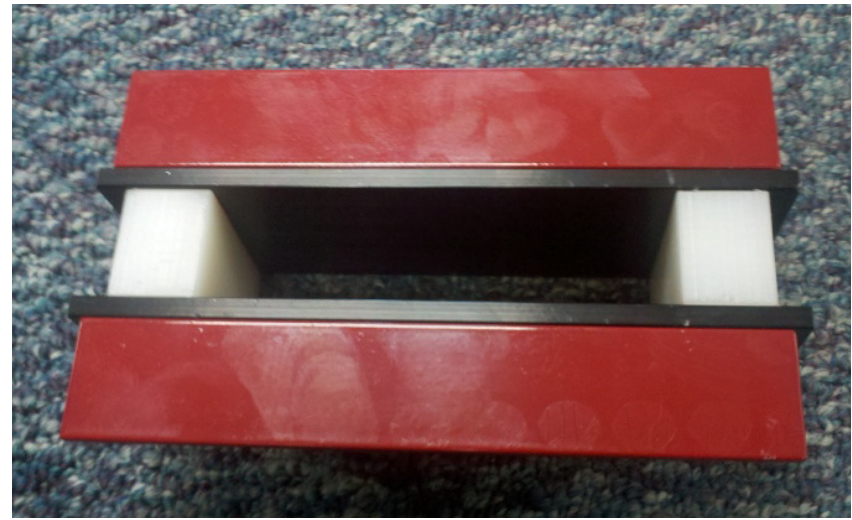

Figure 1. Test frame

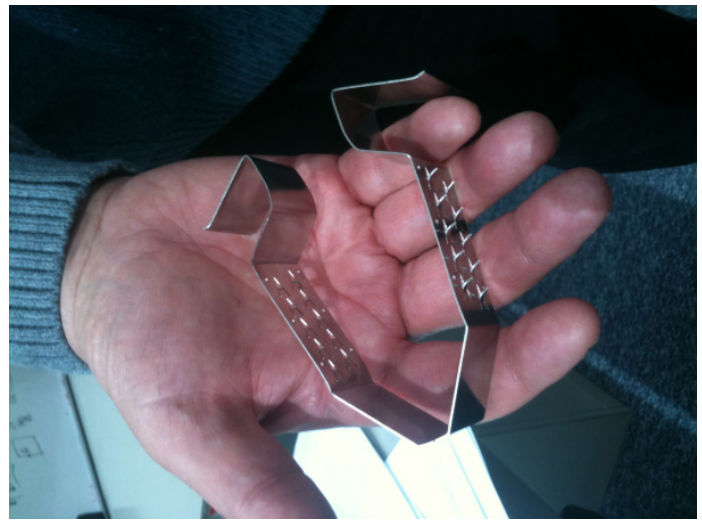

Figure 2. Grounding clip

\section{Initial Effort}

The Conceptual Test Plan (See Appendix A) furnished by Mr. Roth was modified to reflect what the team could do in the INL research environment. It was re-written and submitted to Mr. Roth as a Statement of Work (See Appendix B) defining the task that could be completed, as well as a final report. The three main tasks included:

- Potting for tooth engagement examination

- Ampere loading testing

- Insertion / extraction testing.

For the ampere load test, another description document was written for the battery test laboratory staff to outline the proposed work (see Appendix C). This description document led to the writing of a "Field Change to LI 1305-07-IRC, Battery and Capacitor Testing," document (see Appendix D), which allowed 
battery laboratory testing staff to conduct the proposed work. The "Field Change" document, written by Jeff Belt, lead scientist for the testing done at the battery test laboratory, was reviewed by the facility safety and operations managers and approved.

\section{Conducting the Tests}

The three tasks identified in the Statement of Work were conducted as follows:

\section{Potting Test}

The Potting Test consisted of "potting" the grounding clip/frame plate sample in epoxy then sectioning the sample to characterize the contact points of the clip. This is done to identify locations of contact continuity and to confirm positive underside contact/plate capture after insertion. During the initial Potting Test, the epoxy leaked out of the tape dams and had to be redone. It was initially thought that the epoxy would not hold the clip against the slick side of the anodized aluminum frame, so screws were inserted to hold the assembly together when it was sectioned for analysis. When the potted assembly was cut, the screws were cut away to better show the tooth engagement with the frame plate. The epoxy did not have a complete bond between the clip and the aluminum on one side, so it was recast under a vacuum to force the epoxy into the cracks. Sanding of the sample piece allowed the test technicians to see the engagement of the clip tooth into the aluminum through the anodized layer. Appendix E contains multiple photographs showing the process. The Potting Test was never finished because the funding expired before the sample could be sanded, polished, and photographed. The potted sample will subsequently be returned to Sunlutions so that can complete the testing themselves, if desired.

\section{Ampere Test}

The Ampere Test was conducted to establish the maximum DC amperage that could be conducted through the clip. With only one clip sample available for the test, it was decided to simply "go for it" on the first test, rather than ramping up through a range of tests that could damage the sample. The test was set, and the laboratory technician adjusted the clip a few times to ensure the teeth had scratched through the anodized layer of the frame plate. An initial 10 ampere test was run to check the continuity and conductivity of the clip prior to testing. Following the 10 ampere test, it was decided to conduct a 470 ampere test, which is one of the ranges listed in Underwriter's Laboratory (UL) procedure UL 467Grounding and bonding Equipment Procedure, as shown in Table 1. When the test was started, one of the settings was incorrect and it tripped the breaker on the power supply. The test ran for a couple of milliseconds of 470 amperes and it caused a small spark from the clip. The technicians changed the programming, reset the breaker, tested all of the connections, and ran the test again, resulting in another small spark. As soon as any significant current was applied, a VERY small portion of one of the spikes would melt off and the resulting contact impedance of the clip resting on the anodized aluminum would not allow any current to flow at the maximum voltage of the tester. The technician determined that the only way to carry out the experiment would be to use a tester capable of a much higher open circuit voltage needed to overcome the higher contact impedance. The laboratory has a high voltage system, but it was not available at the time of the test. The ampere test photographs, test graphs and data, and comments from the lead laboratory technician are found in Appendix F. 
Table 1. Section from UL 467 standard on testing

\begin{tabular}{|c|c|c|c|c|c|}
\hline Conduit trade size & $\begin{array}{c}\text { (Metric } \\
\text { designator) }\end{array}$ & $\begin{array}{l}\text { Equipment gro } \\
\text { conductor } \\
\text { AWG or kcmil }\end{array}$ & $\begin{array}{l}\text { nd bonding } \\
\text { apper }) \\
\left\langle\mathrm{mm}^{2}\right\rangle\end{array}$ & Time, s & Test current, A \\
\hline & & $14 \mathrm{AWG}$ & (2.1) & 4 & 300 \\
\hline - & - & 12 & (3.3) & 4 & 470 \\
\hline - & - & 10 & (5.3) & 4 & 750 \\
\hline $1 / 2$ & (16) & 8 & $(8.4)$ & 4 & 1180 \\
\hline $3 / 4,1$ & (21). (27) & 5 & $(13.3\rangle$ & 6 & 1530 \\
\hline $1 \cdot 1 / 4,1 \cdot 1 / 2$ & (35). (41) & 4 & $(21.2)$ & 6 & 2450 \\
\hline
\end{tabular}

\section{Insertion / Extraction Test}

The Insertion/Extraction tests were performed using a \$200,000 Instron tensile testing system to determine the forces exerted during initial tip insertion, teeth insertion (into the anodized frame plate), and clip extraction. Figure 3, with force values displayed in Newtons $(\mathrm{N})$, shows that the grounding clip was actually inserted at about 54 pounds force but required nearly 94 pounds force to insert the teeth onto the aluminum frame. Conversely, it took 66 pounds force to free the teeth and extract the clip from the frame assembly. The multiple photographs contained in Appendix G show the whole story and the printout of the test results shows the values.

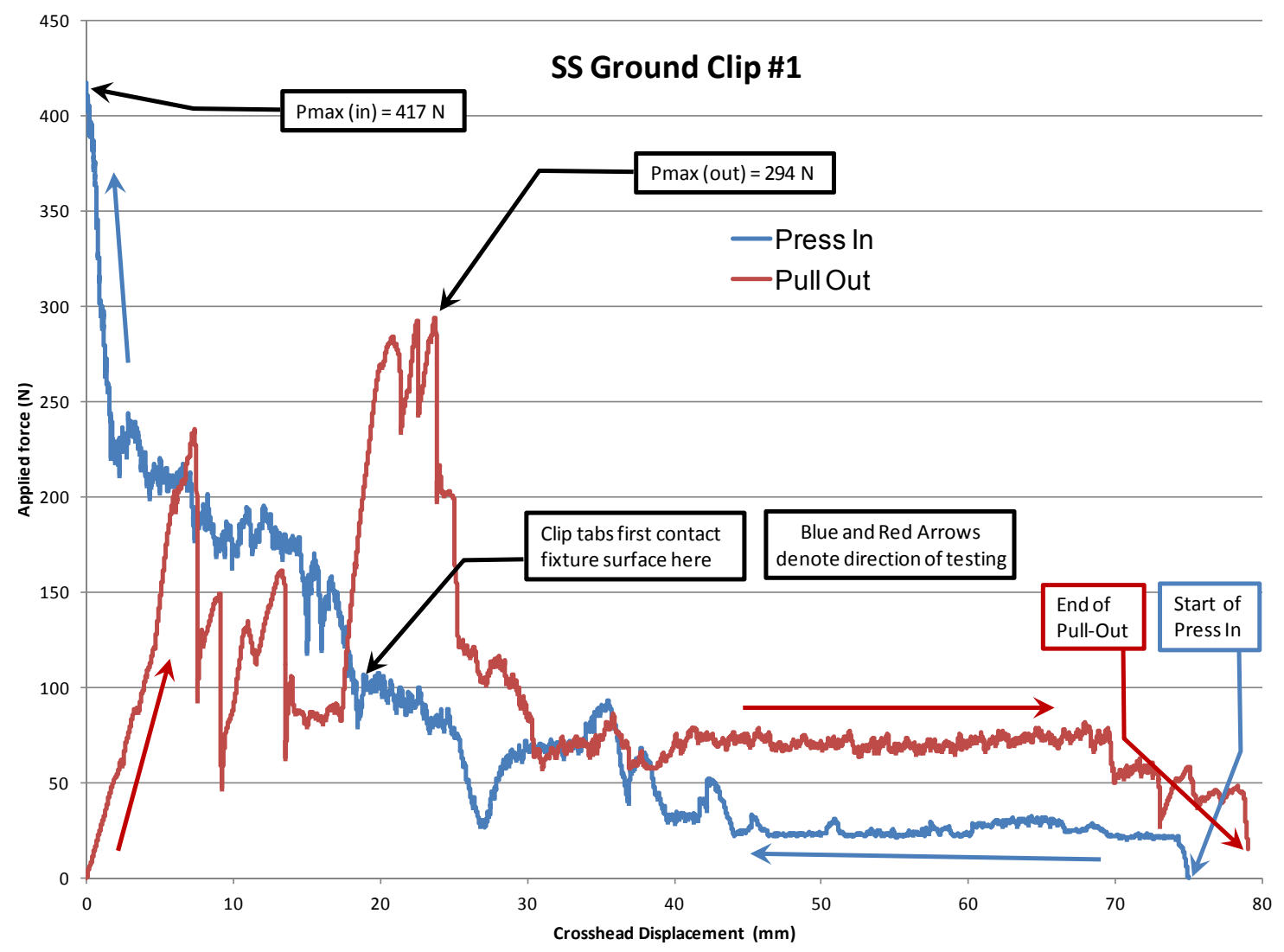

Figure 3. Insertion and extraction force profile 


\section{General Observations}

Some initial observations include:

- The teeth were laser cut, and one tooth was almost cut out by the laser programming.

- Both the angles of the teeth and the stick out of the teeth varied.

- The teeth stick-out and angle variations limited the contact of the clip to the frame to two or three of the longest teeth on each side. The teeth were individually measured, and this record is shown in Appendix H. These teeth were the ones that resulted in burnt off tips during the Ampere Test. They also were the ones that caused the scratches in the anodized coating during the Insertion/Extraction Test. Figure 4 shows a scratch depth of 0.011-inch; Figure 5, shows a solitary scratch on one side of the Insertion/Extraction test. This shows the lack of evenness of the contact of the teeth.

- The clip was too long for the frame sample provided. Eight teeth extended beyond the frame rather than a single row of teeth recommended in the Preliminary Installation Instructions (see Appendix C) provided by Sunlution, LLC.

- The clip was too fat. The clip was bowed from insertion resulting in only a few teeth being engaged with the aluminum frame plate. Maybe the spring of the clip would maintain the grounding or continuity, but that was not the case with this test.

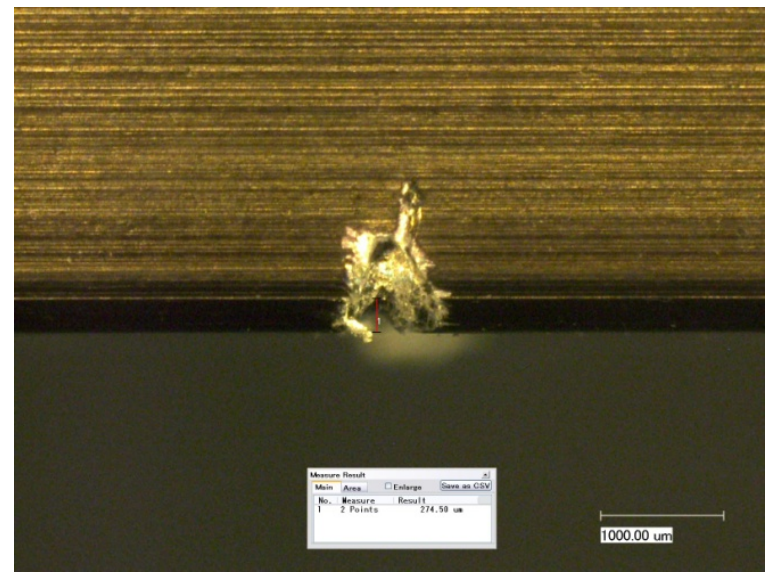

Figure 4. Scratch depth of 275 micrometer,s or 0.011-inch

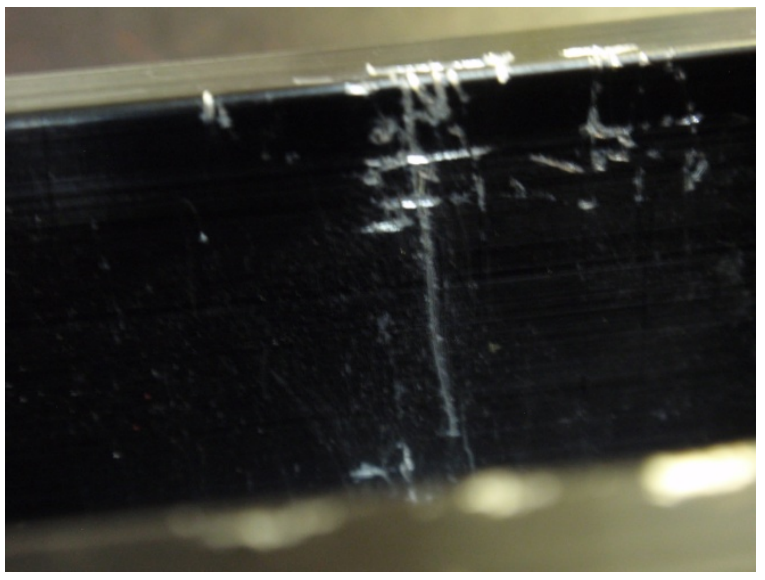

Figure 5. Solitary scratch on one side of insertion/extraction test

\section{Conclusions:}

The test was not as conclusive as hoped. The Potting Test was never finished because of the lack of funding, but photographs readily show scratches by the teeth into the anodized coating. The potted sample is being returned to the customer for their subsequent examination. The Ampere Loading Test didn't have the expected or anticipated out come since the clip did show conductivity and or resistivity. After testing, it was determined that higher voltage test equipment would be a better choice for this testing when attempted in the future. The Insertion / Extraction Test was the most successful and showed that a workman could readily insert and extract the clip.

More sample are needed for subsequent tests, and the clips need to have more exact bending and fabrication to ensure more teeth are in contact with the frame. 
Appendix A

“Preliminary" INL Proof of Concept Test Plan 


\section{Appendix A “Preliminary" INL Proof of Concept Test Plan}

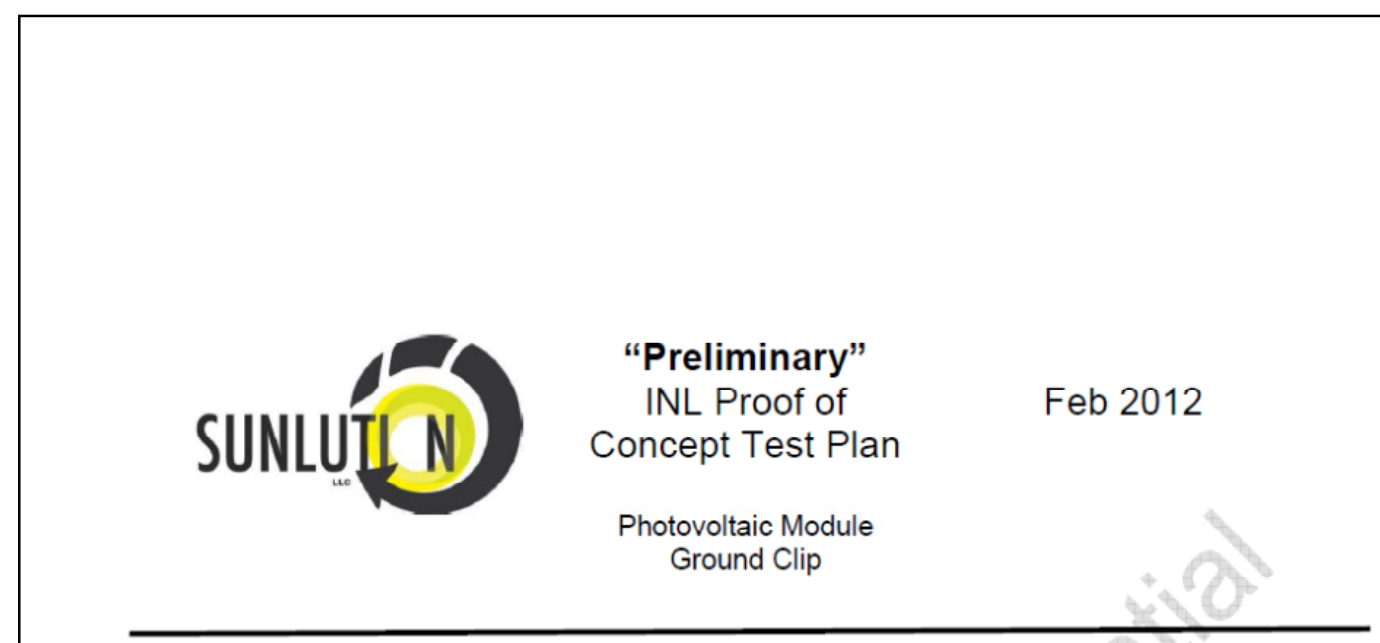

Background - Sunlution LLC has developed a new, novel and proprietary photovoltaic (PV) module grounding device that will attempt to provide a high reliability, high performance, low cost grounding bond between $\mathrm{PV}$ modules with varying module heights and module spacings.

1.0 Purpose - Provide proof of concept testing for PV ground spring under a single simulated PV module height and spacing setup.

2.0 Scope - Provide insertion/extraction force, continuity and maximum amperage testing of ground spring in simulated photovoltaic module mockup using 2 " tall, $.190 "$ thick, $1 "$ nominally spaced aluminum plates with $.001 "$ anodize thickness.

Testing should include the following:

- Confirm positive underside contact/plate capture after insertion.

- Insertion force(s). "Initial tip insertion" and "during teeth insertion".

- Continuity success after single insertion action (ie. Any spring recompression/cycling required to establish continuity?).

- Milliohm resistance plate to plate after continuity is established.

- Thermal cycling after continuity is established $(-20 \mathrm{C}$ to $+80 \mathrm{C})$. Continuity performance based on milliohm resistance plate to plate

- Maximum dc amperage.

- Location(s) of contact continuity (ie. Potting and sectioning of viable contact connections). Destructive.

- Extraction force. Destructive.

3.0 Process

Sunlution to provide 3 preassembled module test mockup fixtures and 3 PV ground spring samples.

See separate recommended installation instructions. 
Appendix B

\section{INL Statement of Work}




\section{Appendix B \\ INL Statement of Work}

\begin{tabular}{|ll|c|}
\hline Identifier: & SOW-???? & $\begin{array}{c}\text { STATEMENT OF WORK } \\
\text { FOR }\end{array}$ \\
Date: & $3 / 12 / 2012$ & SUNLUTION TEST PLAN \\
Revision: & 1 & \\
Page: & 1 of 2 & \\
\hline
\end{tabular}

1. SCOPE

\subsection{Introduction}

Technical Assistance Program (TAP)

Idaho National Laboratory's Technical Assistance Program (TAP), a federallymandated program, authorizes INL to provide knowledge, specialized equipment and limited funding to support for promoting U.S. competitiveness. Through the program, laboratory scientists and engineers provide assistance (40-hours), not normally available to a community or small business, without fees.

Project Background - Sunlution LLC developed a new, novel and proprietary photovoltaic $(\mathrm{PV})$ module grounding device to provide a high reliability, high performance, low cost grounding bond between PV modules with varying module heights and module spacing. Sunlution LLC asked INL TAP to provide assistance with this testing.

\subsection{Test plan from Sunlution Solar Clip}

Initial Scope proposed by Sunlution:

1. Confirm positive underside contact/plate capture after insertion.

2. Insertion force(s). "Initial tip insertion" and "during teeth insertion".

3. Continuity success after single insertion action (ie. Any spring recompression/ cycling required to establish continuity?).

4. Milliohm resistance plate to plate after continuity is established.

5. Thermal cycling after continuity is established $(-20 \mathrm{C}$ to $+80 \mathrm{C})$. Continuity performance based on milliohm resistance plate to plate.

6. Maximum dc amperage. Destructive.

7. Location(s) of contact continuity (ie. Potting and sectioning of viable contact connections). Destructive.

8. Extraction force. Destructive.

\subsection{Test plan revision for Sunlution Solar Clip by INL}

The initial test plan from Sunlution was not achievable by the INL team and especially with the 40 hour funding constraints. The INL team rewrote a subsequent test plan to detail what the team thought they could accomplish in the funding constraints.

Pre-Test setup:

- Characterize/measure clips.

- Drill test holes in sample plates.

- Reserve/schedule lab and equipment

TASK 1: 


\begin{tabular}{|ll|c|}
\hline Identifier: & SOW-???? & STATEMENT OF WORK \\
Date: & $3 / 12 / 2012$ & FOR \\
Revision: & 1 & SUNLUTION TEST PLAN \\
Page: & 2 of 2 & \\
& & \\
\hline
\end{tabular}

- Conduct test $2 \& 8$ (propose to use an Instron system to log the insertion and extraction forces.)

- \#2 - Insertion force(s). "Initial tip insertion" and "during teeth insertion". Can be performed on all 3 samples.

- \#8 - Extraction force. One Sample Only. Destructive.

TASK 2:

- Conduct test 3, 7 - Assisted by Jeff Belt (measurement with a Fluke multimeter)

- \#3 - Continuity success after single insertion action (ie. Any spring recompression/cycling required to establish continuity?).

- \#4 - Milliohm resistance plate to plate after continuity is established.

TASK 3:

- Conduct test 1,4-Assisted by Todd Morris, metallographer (photograph the contacts, pot the sample in epoxy, section the sample to characterize the contact point(s) of the clip).

- \#1 - Confirm positive underside contact/plate capture after insertion. Photo Documentation.

- \#7 - Location(s) of contact continuity (ie. Potting and sectioning of viable contact connections). Epoxy sample and layer cut. One Sample Only. Destructive.

TASK4:

- Conduct test 6 Assisted by Jeff Belt (Conduct amp.

- \#6 - Maximum dc amperage. One Sample Only. Destructive.

TASK 5:

- Compile/organize results

- Produce results/findings.

\subsection{Work Excluded}

5. Thermal cycling after continuity is established $(-20 \mathrm{C}$ to $+80 \mathrm{C})$.

Continuity performance based on milliohm resistance plate to plate.

\section{DELIVERABLES AND SCHEDULE}

Schedule TBD (not to exceed 40 hrs), deliverables identified above and in task list. 
This page intentionally left blank. 
Appendix C

\section{Preliminary Ampere Test Description}




\section{Appendix C \\ Preliminary Ampere Test Description}

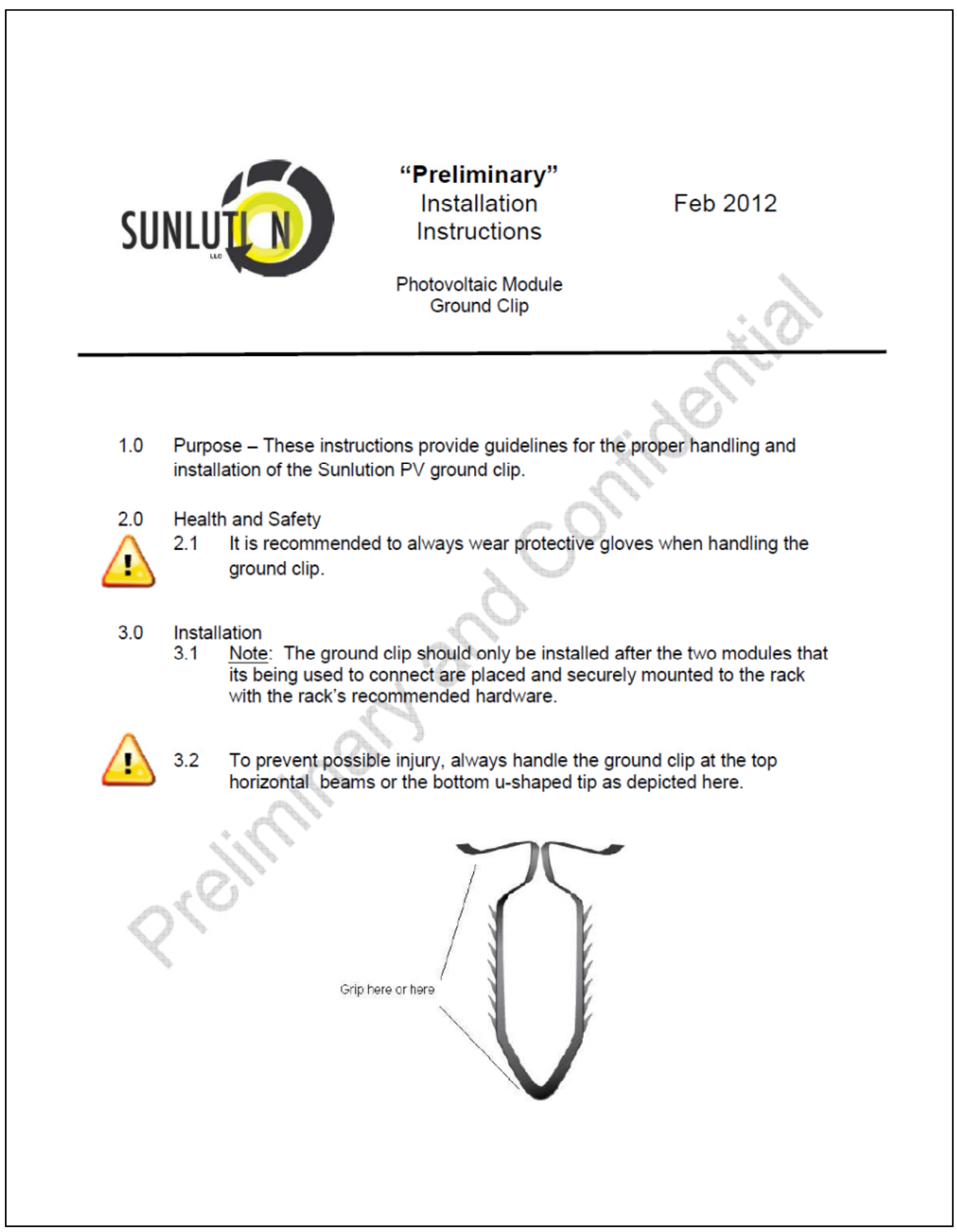


3.3 Grip the outer edges of the top two horizontal beams and squeeze the clip together as depicted here.

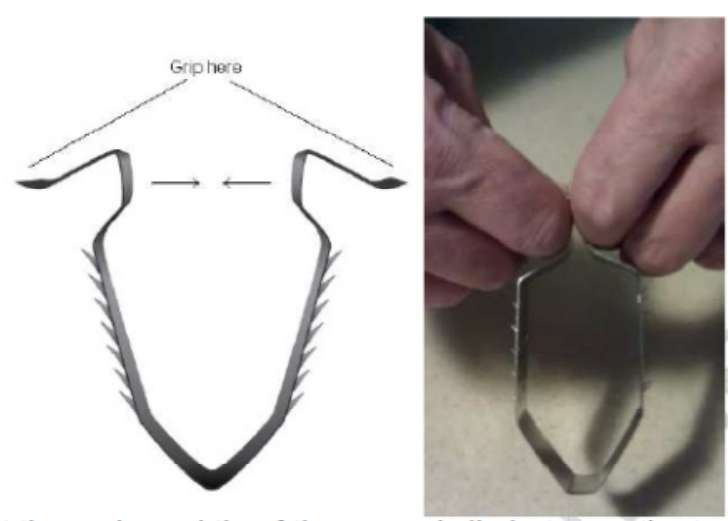

3.4 Insert the u-shaped tip of the ground clip between the two modules as depicted here. Take care to ensure the clip is positioned perpendicular to the top horizontal surfaces of the modules.

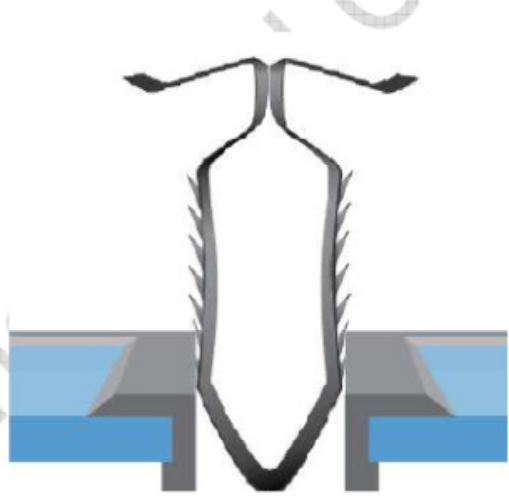


3.5 With the heel of your hand, push the clip straight down between the modules until the top horizontal beams of the clip are deflected and firmly touching the top of the metal frames of the modules as depicted here. Both horizontal beams of the clip should be fully touching and flush on the tops of the module frames.

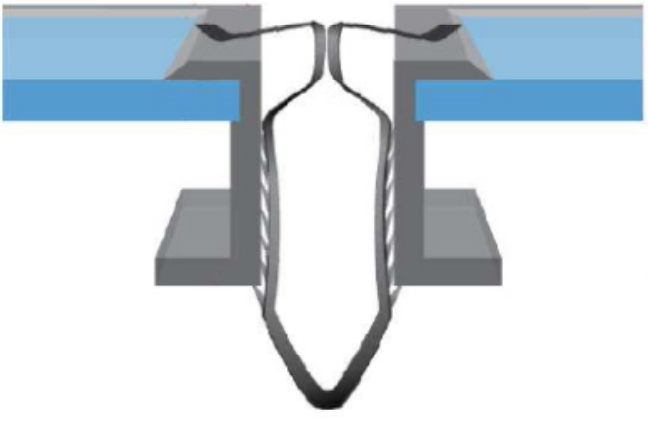

3.6 Check to ensure that at least one row of the clip's teeth on each side of the clip extend outward below the bottom edge of each of the module frames it's connected to.

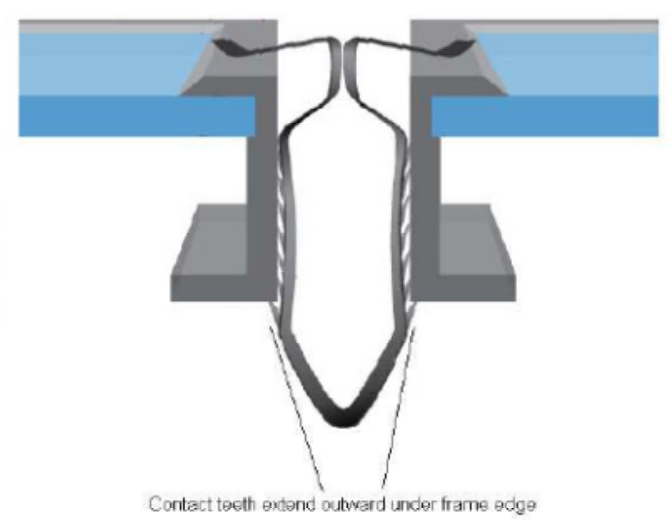


Appendix D

Field Change to LI 1305-07-IRC, Battery and Capacitor Testing 


\title{
Appendix D \\ Field Change to LI 1305-07-IRC, Battery and Capacitor Testing
}

\author{
Field Change to LI 1305-07-IRC, Battery and Capacitor Testing
}

\section{Purpose:}

The purpose of this work is to perform conductivity and failure tests on a grounding clip (shown below) in the Energy Storage and Transportation Laboratory also called the Battery Laboratory (IF605). The plan is to use 2- 5 Volt, $250 \mathrm{Amp}$ channels in parallel to perform the tests. If $500 \mathrm{Amps}$ at less than 5 Volts is not enough to cause failure, then 4 channels will be paralleled to provide $1000 \mathrm{Amps}$.

\section{Basic Test Steps:}

One clip shall be inserted into the prototype fixture and delivered. Assistance from the Battery Laboratory is detailed and limited to the following task list:

- Measure, with a test instrument, the continuity and milliohm resistance of one (but maybe three clips) clip in a prototype fixture. The photos below show the clip and it being tested and this test needs to be duplicated.

- Attach the probes to the ends of the fixture

- Measure the continuity, by performing a series of current pulses necessary to produce a reasonable voltage drop.

- Measure the milliohm resistance

○ Record the values on a test sheet

The short-time current test is not shown by photographs but lugs for cables shall be welded or bolted onto the black anodized aluminum before testing. The task to conduct a current test is listed below. These values are based on the UL 467 Grounding and Bonding procedure. The table from this procedure is listed below.

- Connect the ampere generating system cables to each side of the fixture

- Connect data acquisition cables to the clip fixture and to the data system

- Program the setting of the test

- Energize the systems

- Observe if the clip teeth melt off

- If the clip teeth do not melt off, repeat the test with 300 amperes for 4 seconds

- If the clip teeth do not melt off, repeat the test with 470 amperes for 4 seconds

- If the clip teeth do not melt off, repeat the test with 750 amperes for 4 seconds

- Record the results of the test on a test sheet

- Terminate the test, and clean any debris created by the test.

\section{Duration:}

One time activity

Hazard Mitigation (not encompassed by LI)

The current $\mathrm{LI}$ encompasses similar testing on batteries, which tend to be more hazardous than a grounding clip. Batteries and terminals occasionally fail during testing inside the temperature chambers. 
The test will occur on a metal table or rolling cart and with a lexan box to facilitate viewing the test and to contain hot metal or sparks. The clip will get hot, but is very thin (0.20-inch thick and 1 -inch wide) and does not represent a very heavy sample with any substantial mass.

No waste other than municipal waste is expected to be generated. The test fixture and grounding clips will be returned to the customer

Grounding clip test. The grounding clip shown below grounds the frames of solar panels.

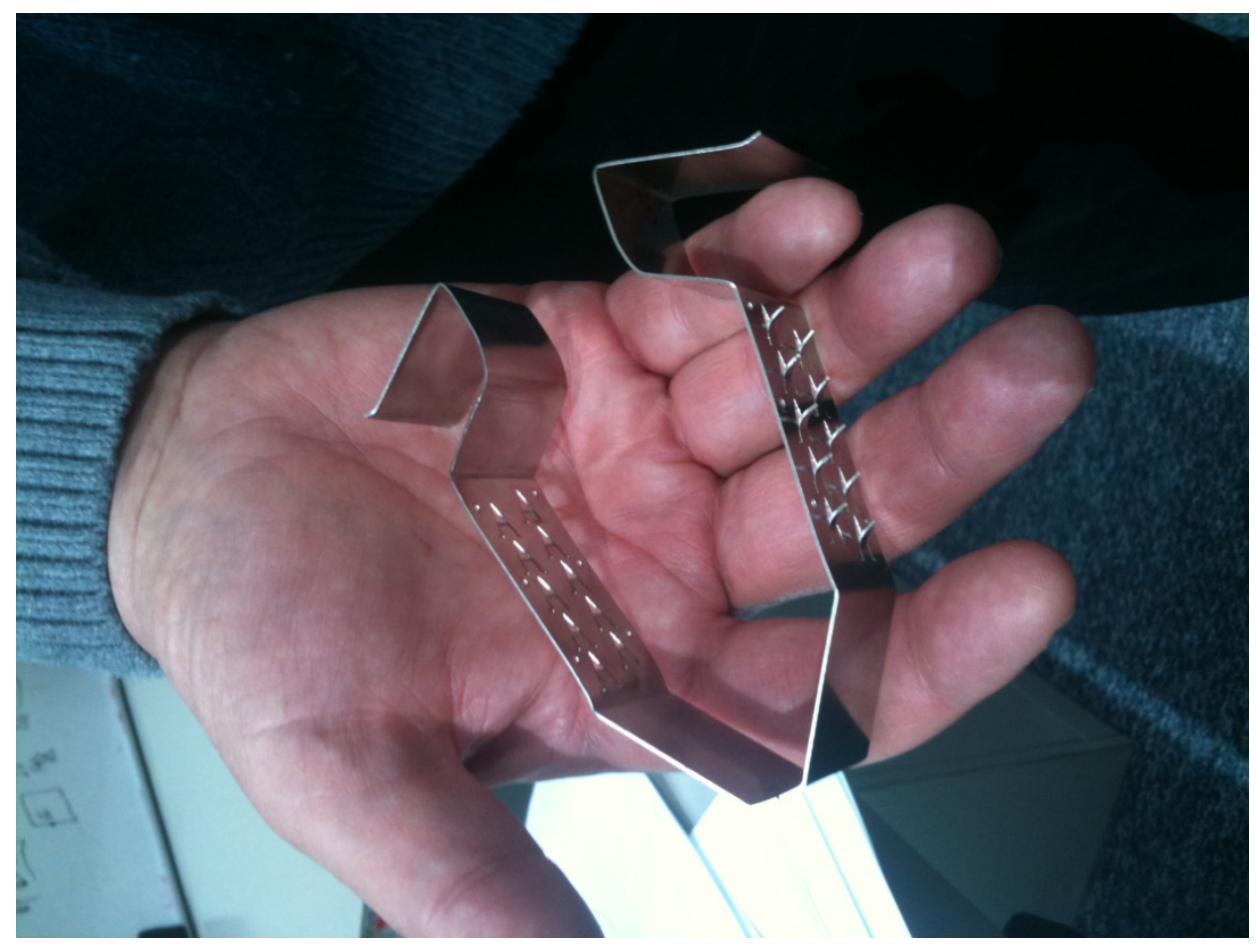

After the grounding clip is inserted in a prototype configuration, tests need to be performed to provide an initial characterization of it functionality. The prototype configuration is shown in the photograph below. 


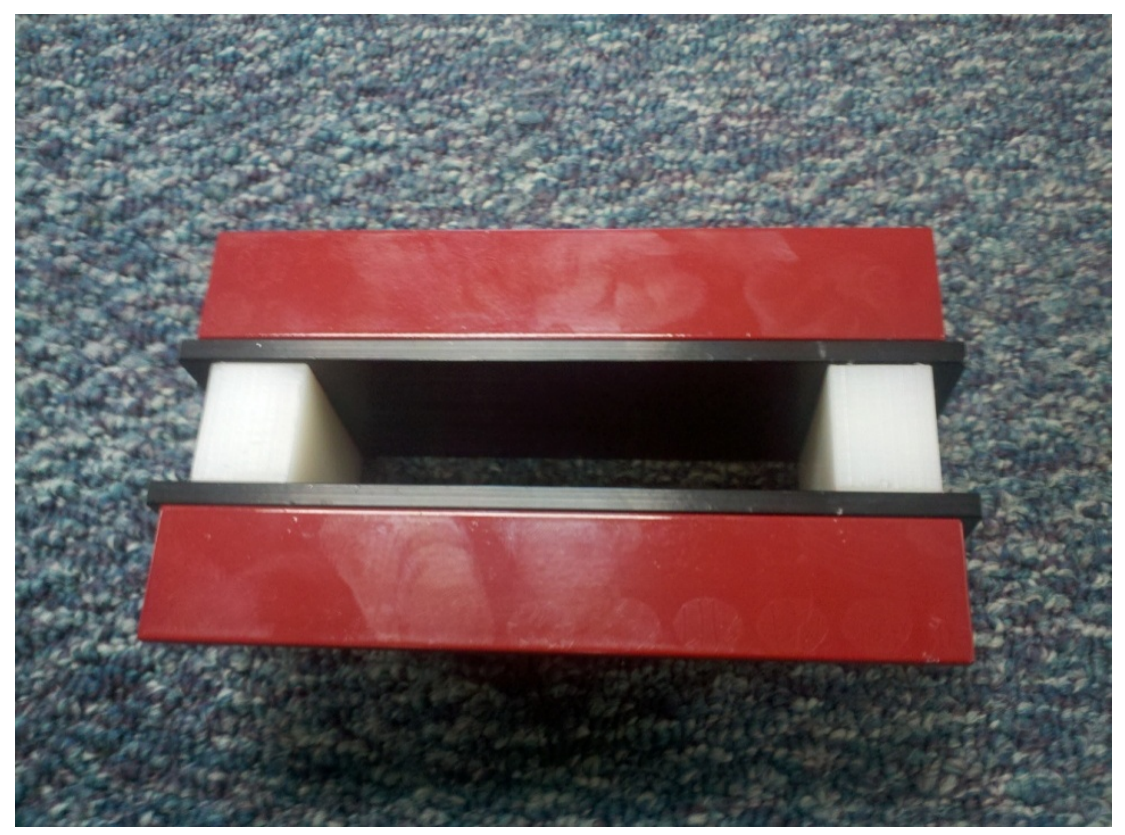

A photograph showing a clip being tested for continuity and resistivity in a prototype configuration is shown below.

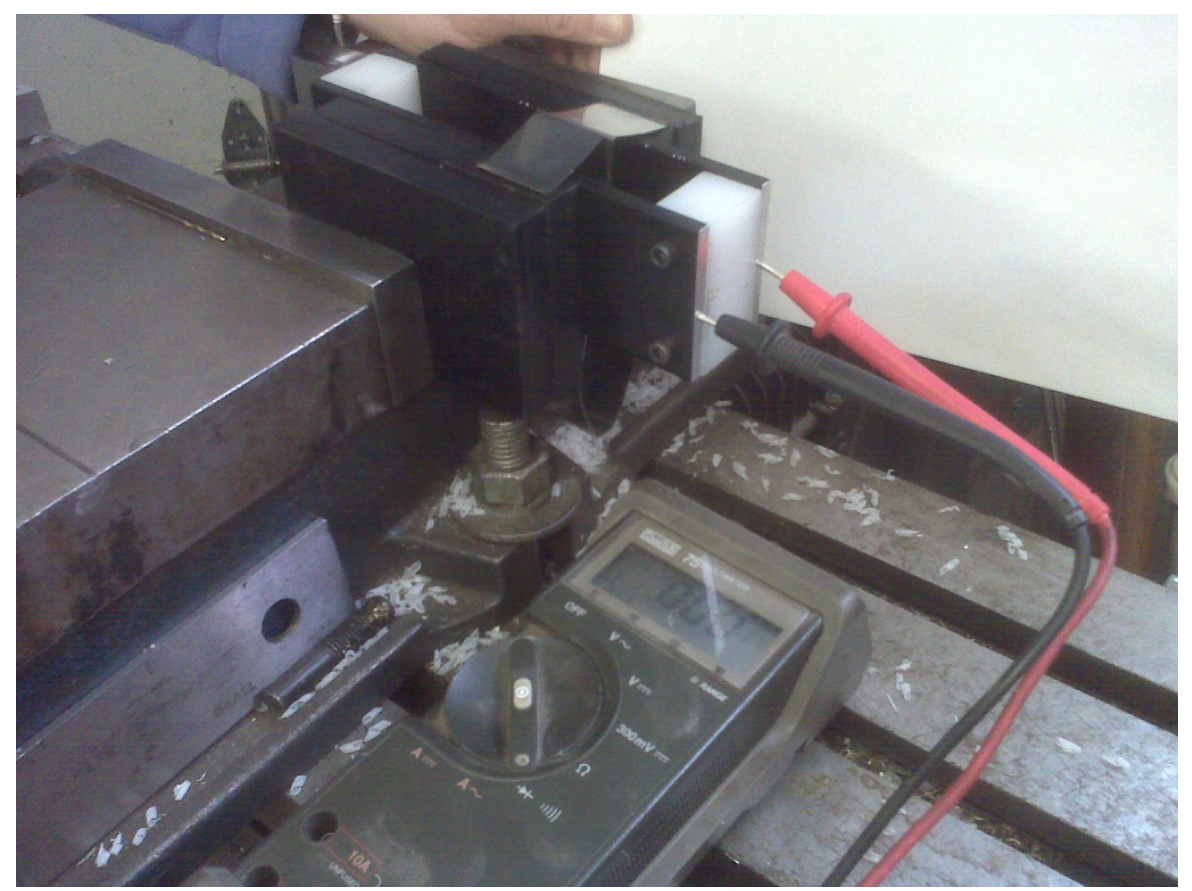




\section{Current Test}

14,1 A grounding or bonding fitting shall carry the currenl specified in Table 14,1 lor the time specified in that table. The current shall be based on either the conduit size involved or the largest size of wire for which the fitting is marked, whichever is less. The fitting shall not crack, break, or melt. Arcing and burning of a throat insulator is acceptable.

Table 14.1

Short-time test currents

\begin{tabular}{|c|c|c|c|c|c|}
\hline Conduit trade size & $\begin{array}{c}\text { (Metric } \\
\text { designator) }\end{array}$ & $\begin{array}{l}\text { Equipment gros } \\
\text { conductor } \\
\text { AWG or kcmil }\end{array}$ & $\begin{array}{l}\text { nd bonding } \\
\text { aper }) \text {, } \\
\left\langle\mathrm{mm}^{2}\right\rangle\end{array}$ & Time, s & Test current, A \\
\hline & & 14 AWG & $(2.1)$ & 4 & 300 \\
\hline - & - & 12 & (3.3) & 4 & 470 \\
\hline $3 / 4,1$ & (21), (27) & 5 & (13.3) & 6 & 1530 \\
\hline $1 \cdot 1 / 4,1 \cdot 1 / 2$ & $(35),(41)$ & 4 & $|21.2\rangle$ & 6 & 2450 \\
\hline
\end{tabular}

This table is from the UL 467--Grounding and Bonding Equipment procedure. This procedure shows the suggested test time and ampere settings. 
This page intentionally left blank. 
Appendix E

Potting Photographs 


\section{Appendix E Potting Photographs}

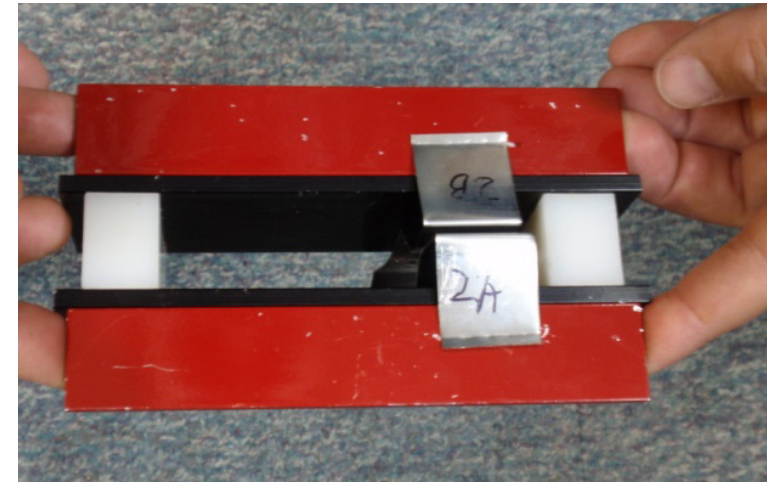

Clip inserted into frame-misalignment

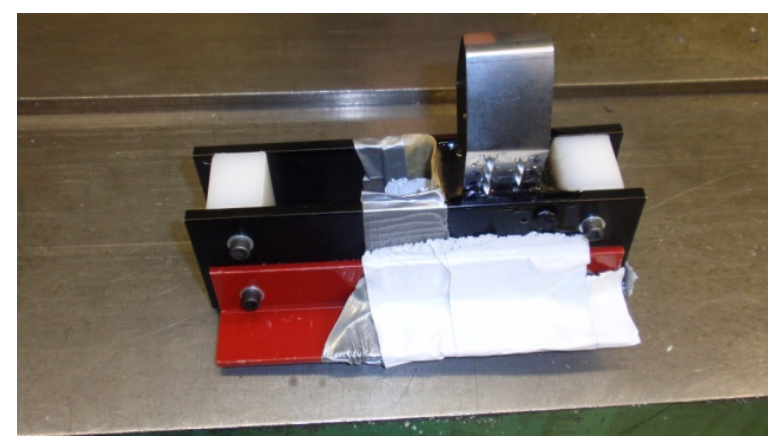

Clip set into frame with epoxy

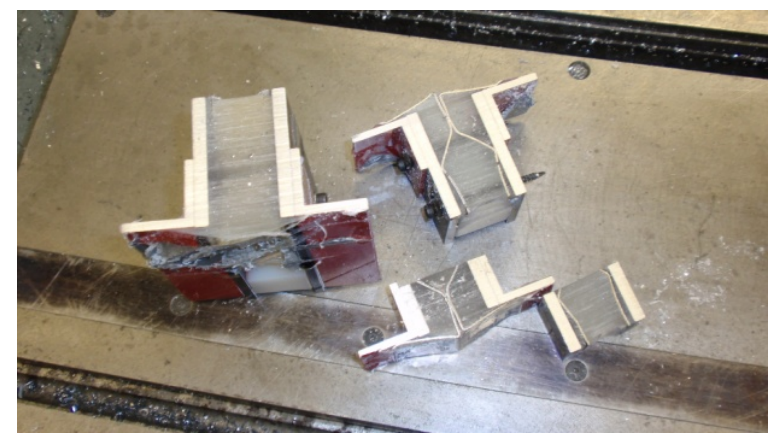

Cut up pieces from potted clip

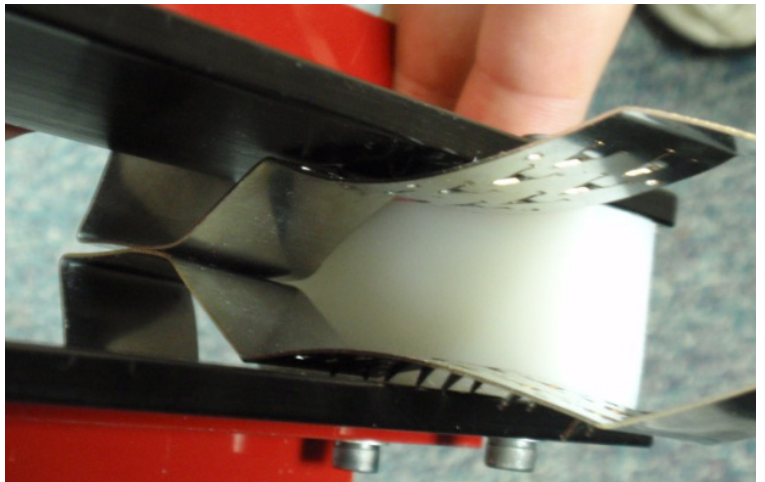

Not all teeth touching frame

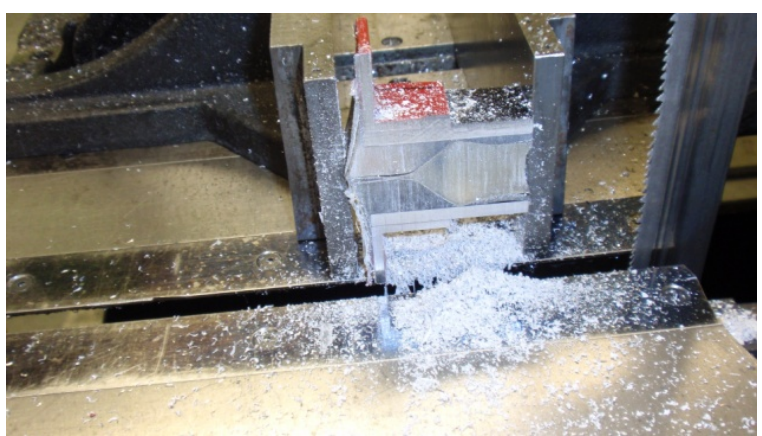

Saw cutting the potted clip

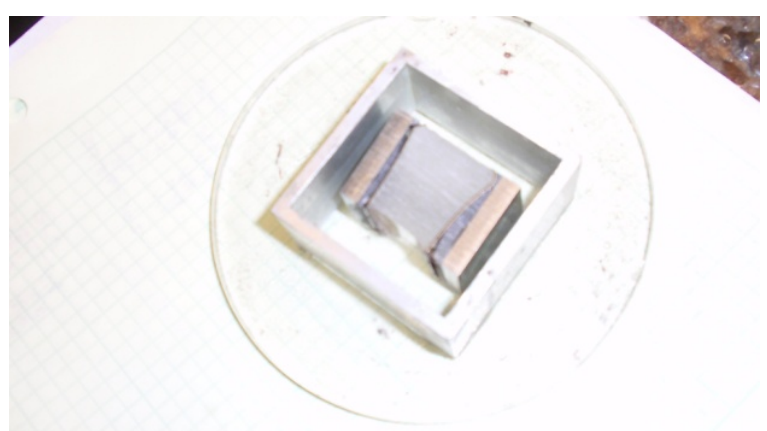

Tooth touching section re-potted--separating 


\section{Appendix F}

\section{Ampere Test Photographs, Technician Comments, Graphs, and Data}




\section{Appendix $F$ \\ Ampere Test Photographs, Technician Comments, Graphs, and Data}

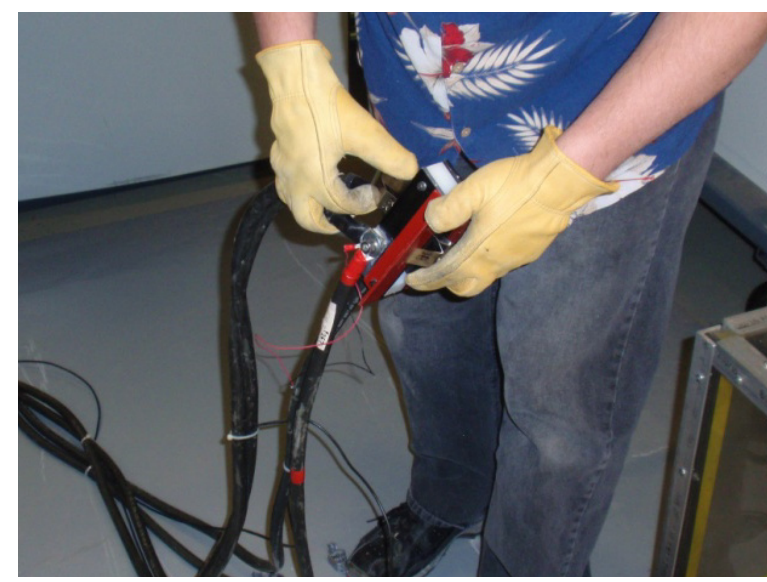

Inserting and wiggling clip in fixture

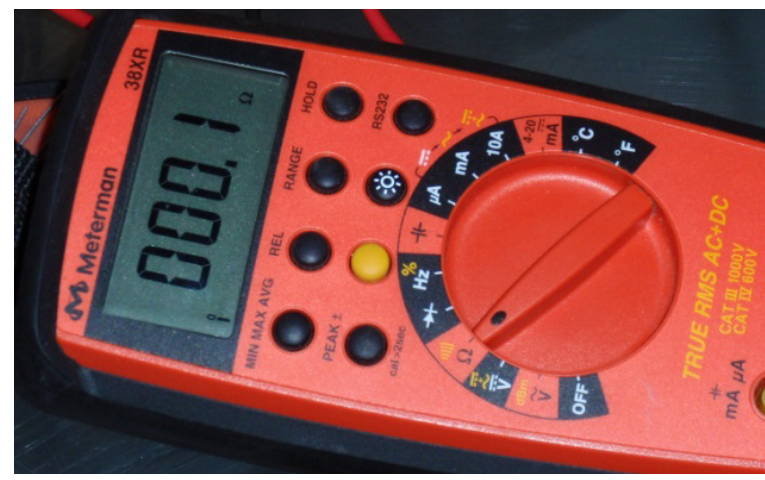

Dead short between fixture by clip

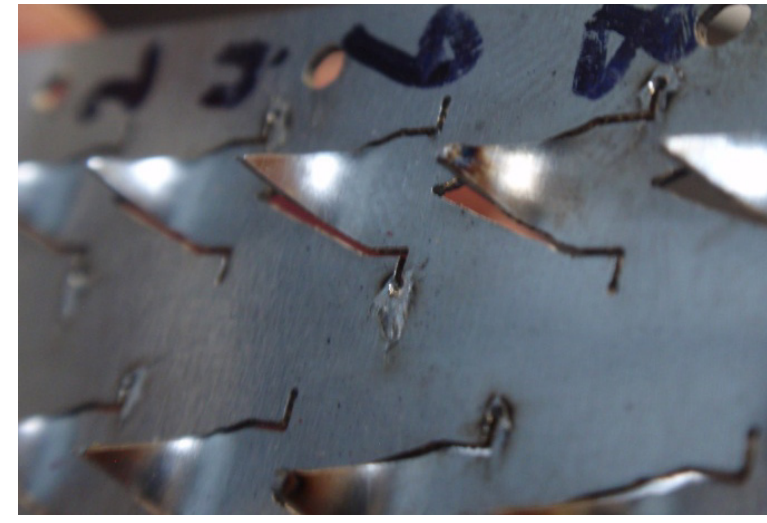

Two teeth tips burnt off

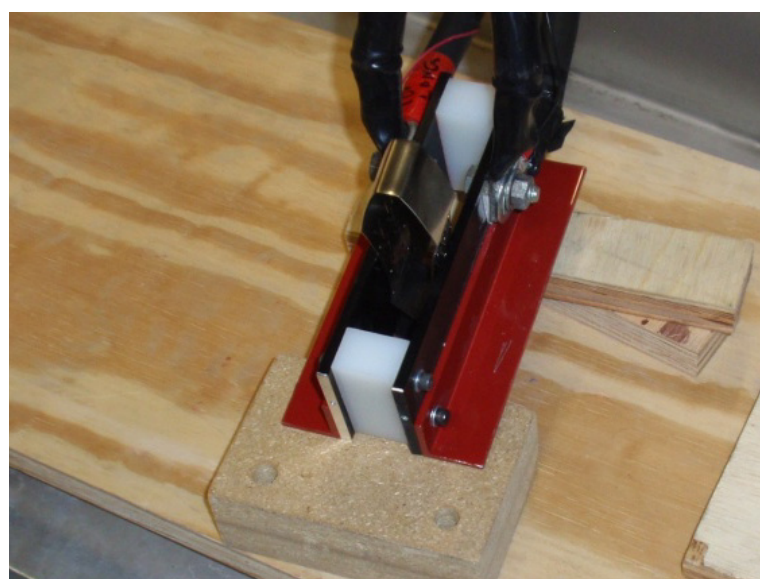

Fixture with cables set on floor for testing

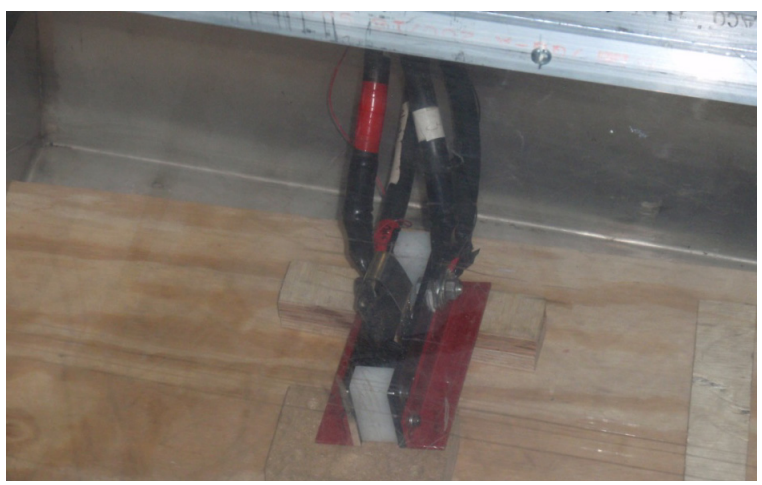

Plastic cover of test sample

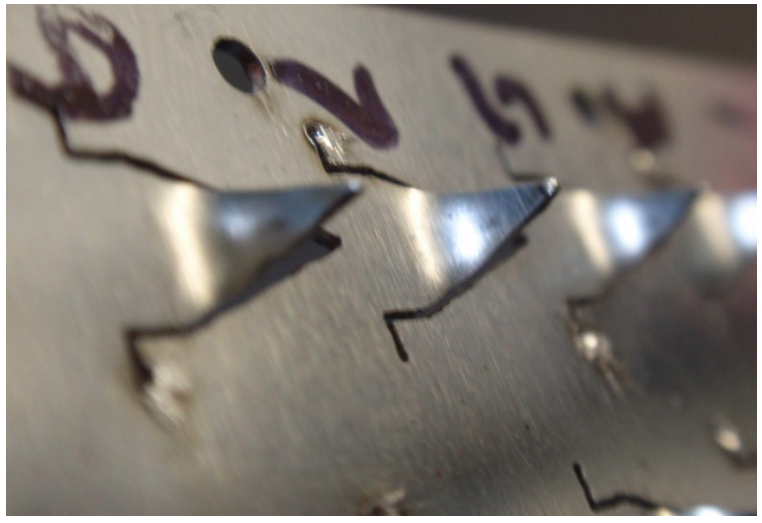

One tooth tip burnt off 


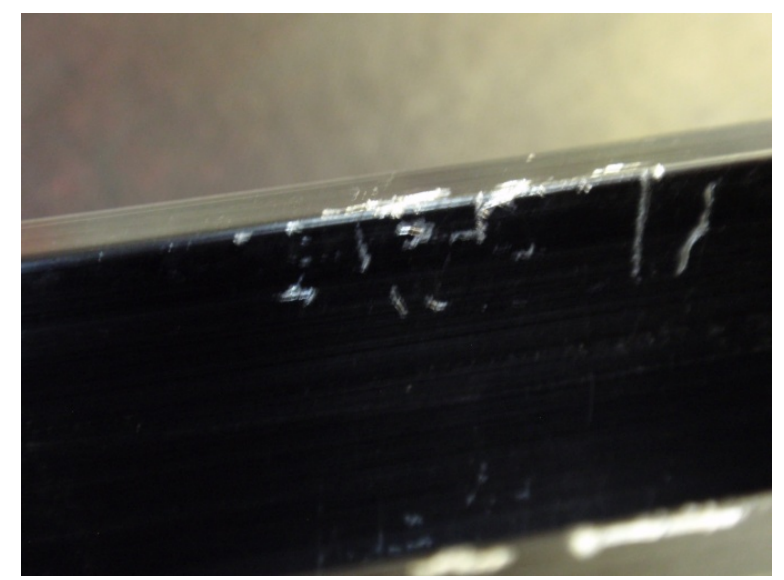

Scratches on one side of frame

Note from Amp Test Technician:

I have created three $X L$ files for you to look at. The first is the $20 \mathrm{Amp}$ run. This is the run were we limited the current to 20 amps in order to get a feel for the impedance we would be dealing with. The files are setup so that the first tab is a graph of the run and the second tab is the numerical values show in the graph on the first tab. The instantaneous impedance can be calculated by taking any of the voltage values and dividing it by the corresponding current. The impedance was around $0.028 \mathrm{ohms}$. The other two files show what happened when we tried to apply 5 volts at 470 Amps. There was an initial pulse of current, then the impedance increased, and the voltage was limited by the capabilities of the system. I don't believe this is a fair test of the clip, as there is a voltage limit of 5 volts. Since the clip will be in a situation where the voltage is almost unlimited,

The test really needs to be performed on a system with a higher voltage capability. Also keep in mind that while the data indicates that the current never rose above $150 \mathrm{~mA}$, the data rate of the system is limited to $10 \mathrm{mS}$. I'm sure that the instantaneous current was much higher than that, the system is just not capable of capturing data that fast. I have the videos of the test if you would like to come by and get them. Or, if you can give me access to a network server, I would be happy to upload them. If you need any further help, please let me know. Thanks.... 


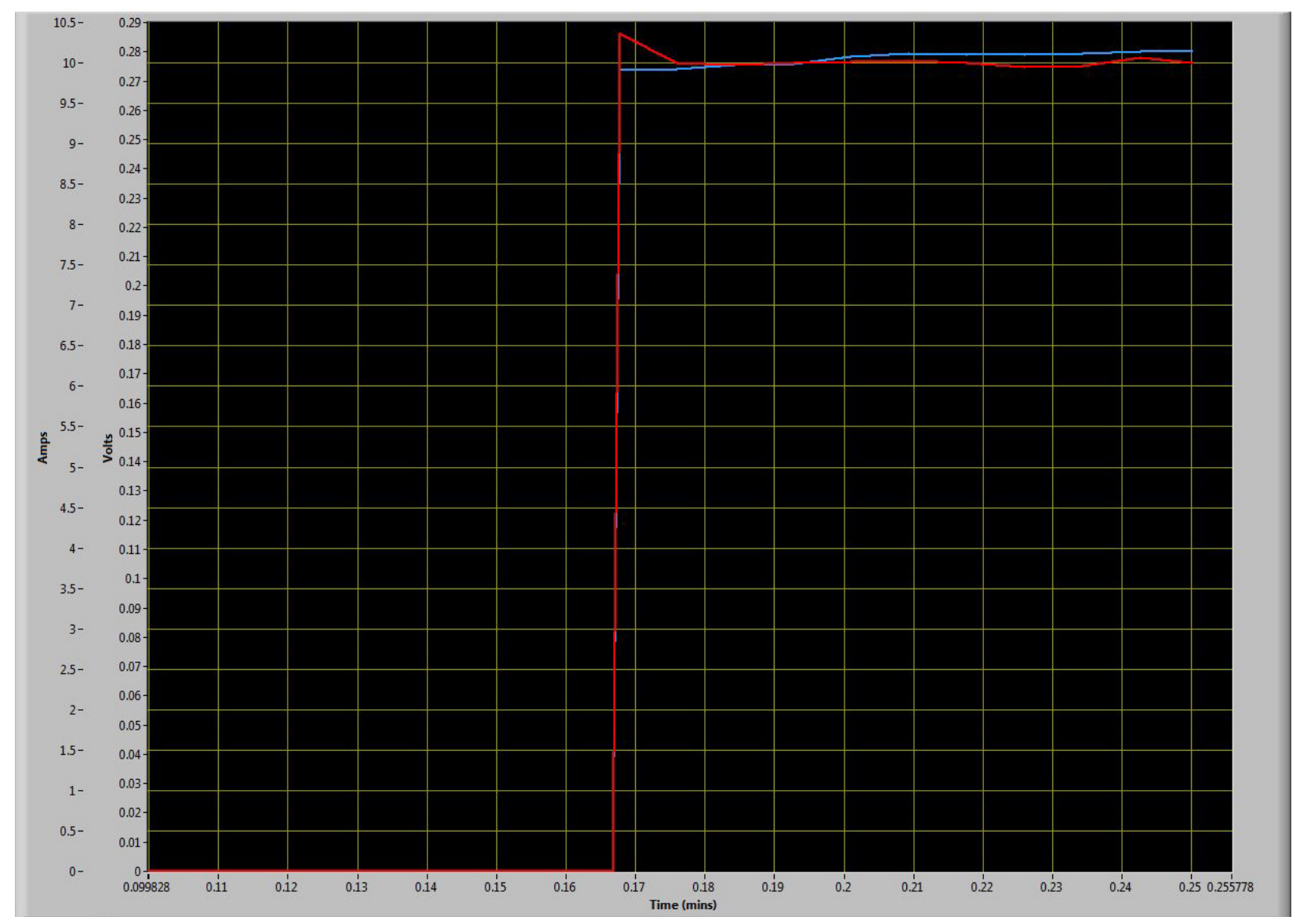

\begin{tabular}{|r|r|r|}
\hline \multicolumn{1}{|l|}{$\begin{array}{r}\text { Time } \\
\text { (minuets) }\end{array}$} & \multicolumn{2}{|l|}{ Amps } \\
\hline 0.1022 & 0 & 0 \\
\hline 0.1188 & 0 & 0 \\
\hline 0.1355 & 0 & 0 \\
\hline 0.1522 & 0 & 0 \\
\hline 0.1667 & 0 & $7.63 \mathrm{E}-05$ \\
\hline 0.1677 & 10.3609 & 0.273747 \\
\hline 0.176 & 9.99466 & 0.274205 \\
\hline 0.1843 & 9.9794 & 0.275654 \\
\hline 0.1927 & 9.99466 & 0.275883 \\
\hline 0.201 & 10.0099 & 0.278172 \\
\hline 0.2093 & 10.0252 & 0.27924 \\
\hline 0.2177 & 9.99466 & 0.279011 \\
\hline 0.226 & 9.94888 & 0.279164 \\
\hline 0.2343 & 9.96414 & 0.279469 \\
\hline 0.2427 & 10.071 & 0.280156 \\
\hline 0.25 & 9.99466 & 0.280232 \\
\hline & & \\
\hline & & 0 \\
\hline
\end{tabular}


Note from the Amp Test Technician:

As you know we carried out the failure test of the grounding clip on 3/30/2012. The results were somewhat inconclusive.

I have attached the two most relevant data files to this note. The files are a coma delimited spreadsheet format. In the first file (Clip1-0005.csv) you can see that we held 10 amps of current for approx. 5 seconds to determine the impedance of the clip before testing. With a nominal current of $10 \mathrm{~A}$ and a voltage of $0.276 \mathrm{~V}$, we get $0.027 \mathrm{ohms}$. The other file shows the type of data we collected during subsequent runs. As soon as we applied any significant current, a VERY small portion of one of the spikes would melt off and the resulting contact impedance of the clip resting on the anodized aluminum would not allow any current to flow at the maximum voltage of the tester. I believe the only way to carry out this experiment is to use a tester capable of much higher open circuit voltage. The higher voltage is needed to overcome the higher contact impedance.

There were also videos taken of the event, however I do not have the necessary software to edit them to a reasonable length. I have uploaded them to our data server, and Jeff can help you extract them if needed. At approx. 1 min. 18 seconds into file M2U00261.MPG you will see a small spark indicating when the current was started. If you would like a more detailed and formal analysis of the data and the procedure, I'm sure we could work that out through our management. And if you would like copies of all the data files, please don't hesitate to call or write. 


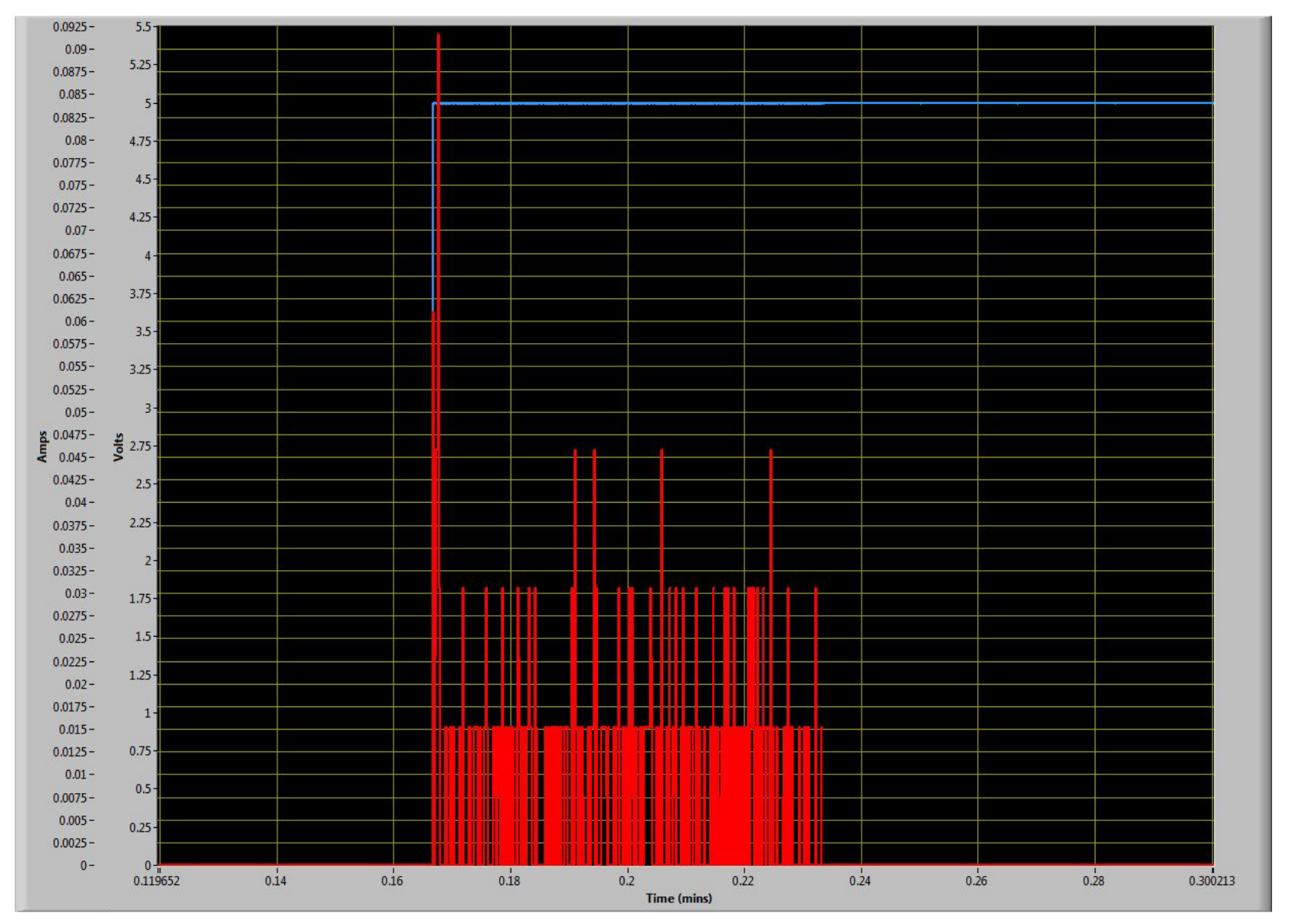

\begin{tabular}{|r|r|r|}
\hline $\begin{array}{r}\text { Time } \\
\text { (minuets) }\end{array}$ & \multicolumn{1}{l|}{ Amps } \\
\hline 0.1333 & 0 & 0 \\
\hline 0.15 & 0 & 0 \\
\hline 0.1667 & 0 & 0 \\
\hline 0.1668 & 0.0610361 & 5 \\
\hline 0.167 & 0 & 5 \\
\hline 0.1672 & 0.0457771 & 5 \\
\hline 0.1673 & 0.0457771 & 5 \\
\hline 0.1675 & 0.0457771 & 5 \\
\hline 0.1677 & 0.0915541 & 5 \\
\hline 0.1678 & 0.030518 & 5 \\
\hline 0.168 & 0 & 5 \\
\hline 0.1682 & 0 & 5 \\
\hline 0.1683 & 0 & 5 \\
\hline 0.1685 & 0 & 5 \\
\hline 0.1687 & 0 & 5 \\
\hline 0.1688 & 0.015259 & 5 \\
\hline 0.169 & 0.015259 & 5 \\
\hline
\end{tabular}

\begin{tabular}{|r|r|r|}
\hline 0.1692 & 0 & 5 \\
\hline 0.1693 & 0 & 5 \\
\hline 0.1695 & 0 & 5 \\
\hline 0.1697 & 0.015259 & 5 \\
\hline 0.1698 & 0.015259 & 5 \\
\hline 0.17 & 0 & 5 \\
\hline 0.1702 & 0 & 5 \\
\hline 0.1703 & 0.015259 & 5 \\
\hline 0.1705 & 0 & 5 \\
\hline 0.1707 & 0 & 5 \\
\hline 0.1708 & 0 & 5 \\
\hline 0.171 & 0 & 5 \\
\hline 0.1712 & 0 & 5 \\
\hline 0.1713 & 0.015259 & 5 \\
\hline 0.1715 & 0 & 5 \\
\hline 0.1717 & 0 & 5 \\
\hline 0.1718 & 0.030518 & 5 \\
\hline 0.172 & 0 & 5 \\
\hline 0.1722 & 0 & 5 \\
\hline & & \\
\hline
\end{tabular}




\begin{tabular}{|c|c|c|}
\hline 0.1723 & 0 & 5 \\
\hline 0.1725 & 0 & 5 \\
\hline 0.1727 & 0 & 5 \\
\hline 0.1728 & 0.015259 & 5 \\
\hline 0.173 & 0.015259 & 5 \\
\hline 0.1732 & 0 & 5 \\
\hline 0.1733 & 0 & 5 \\
\hline 0.1735 & 0 & 5 \\
\hline 0.1737 & 0.015259 & 5 \\
\hline 0.1738 & 0.015259 & 5 \\
\hline 0.174 & 0.015259 & 5 \\
\hline 0.1742 & 0.015259 & 5 \\
\hline 0.1743 & 0.015259 & 5 \\
\hline 0.1745 & 0 & 5 \\
\hline 0.1747 & 0.015259 & 5 \\
\hline 0.1748 & 0.015259 & 5 \\
\hline 0.175 & 0 & 5 \\
\hline 0.1752 & 0 & 5 \\
\hline 0.1753 & 0 & 5 \\
\hline 0.1755 & 0.015259 & 5 \\
\hline 0.1757 & 0.015259 & 5 \\
\hline 0.1758 & 0.030518 & 5 \\
\hline 0.176 & 0.015259 & 5 \\
\hline 0.1762 & 0 & 5 \\
\hline 0.1763 & 0 & 5 \\
\hline 0.1765 & 0 & 5 \\
\hline 0.1767 & 0 & 5 \\
\hline 0.1768 & 0 & 5 \\
\hline 0.177 & 0.015259 & 5 \\
\hline 0.1772 & 0.015259 & 5 \\
\hline 0.1773 & 0.015259 & 5 \\
\hline 0.1775 & 0 & 5 \\
\hline 0.1777 & 0 & 5 \\
\hline 0.1778 & 0.015259 & 5 \\
\hline 0.178 & 0.015259 & 5 \\
\hline 0.1782 & 0 & 5 \\
\hline 0.1783 & 0.015259 & 5 \\
\hline 0.1785 & 0 & 5 \\
\hline 0.1787 & 0.030518 & 5 \\
\hline 0.1788 & 0 & 5 \\
\hline 0.179 & 0 & 5 \\
\hline
\end{tabular}

\begin{tabular}{|c|c|c|}
\hline 0.1792 & 0.015259 & 5 \\
\hline 0.1793 & 0 & 5 \\
\hline 0.1795 & 0.015259 & 5 \\
\hline 0.1797 & 0 & 5 \\
\hline 0.1798 & 0 & 5 \\
\hline 0.18 & 0.015259 & 5 \\
\hline 0.1802 & 0 & 5 \\
\hline 0.1803 & 0.015259 & 5 \\
\hline 0.1805 & 0 & 5 \\
\hline 0.1807 & 0 & 5 \\
\hline 0.1808 & 0 & 5 \\
\hline 0.181 & 0.015259 & 5 \\
\hline 0.1812 & 0 & 5 \\
\hline 0.1813 & 0.030518 & 5 \\
\hline 0.1815 & 0.015259 & 5 \\
\hline 0.1817 & 0.015259 & 5 \\
\hline 0.1818 & 0 & 5 \\
\hline 0.182 & 0.015259 & 5 \\
\hline 0.1822 & 0 & 5 \\
\hline 0.1823 & 0 & 5 \\
\hline 0.1825 & 0.015259 & 5 \\
\hline 0.1827 & 0 & 5 \\
\hline 0.1828 & 0.015259 & 5 \\
\hline 0.183 & 0.015259 & 5 \\
\hline 0.1832 & 0.030518 & 5 \\
\hline 0.1833 & 0.015259 & 5 \\
\hline 0.1835 & 0.015259 & 5 \\
\hline 0.1837 & 0 & 5 \\
\hline 0.1838 & 0 & 5 \\
\hline 0.184 & 0 & 5 \\
\hline 0.1842 & 0.030518 & 5 \\
\hline 0.1843 & 0.015259 & 5 \\
\hline 0.1845 & 0 & 5 \\
\hline 0.1847 & 0 & 5 \\
\hline 0.1848 & 0 & 5 \\
\hline 0.185 & 0 & 5 \\
\hline 0.1852 & 0 & 5 \\
\hline 0.1853 & 0 & 5 \\
\hline 0.1855 & 0 & 5 \\
\hline 0.1857 & 0 & 5 \\
\hline 0.1858 & 0 & 5 \\
\hline
\end{tabular}




\begin{tabular}{|c|c|c|}
\hline 0.186 & 0.015259 & 5 \\
\hline 0.1862 & 0 & 5 \\
\hline 0.1863 & 0 & 5 \\
\hline 0.1865 & 0.015259 & 5 \\
\hline 0.1867 & 0 & 5 \\
\hline 0.1868 & 0 & 5 \\
\hline 0.187 & 0.015259 & 5 \\
\hline 0.1872 & 0.015259 & 5 \\
\hline 0.1873 & 0 & 5 \\
\hline 0.1875 & 0.015259 & 5 \\
\hline 0.1877 & 0.015259 & 5 \\
\hline 0.1878 & 0 & 5 \\
\hline 0.188 & 0.015259 & 5 \\
\hline 0.1882 & 0 & 5 \\
\hline 0.1883 & 0 & 5 \\
\hline 0.1885 & 0.015259 & 5 \\
\hline 0.1887 & 0.015259 & 5 \\
\hline 0.1888 & 0 & 5 \\
\hline 0.189 & 0 & 5 \\
\hline 0.1892 & 0.015259 & 5 \\
\hline 0.1893 & 0.015259 & 5 \\
\hline 0.1895 & 0.015259 & 5 \\
\hline 0.1897 & 0.015259 & 5 \\
\hline 0.1898 & 0 & 5 \\
\hline 0.19 & 0 & 5 \\
\hline 0.1902 & 0 & 5 \\
\hline 0.1903 & 0 & 5 \\
\hline 0.1905 & 0.030518 & 5 \\
\hline 0.1907 & 0 & 5 \\
\hline 0.1908 & 0 & 5 \\
\hline 0.191 & 0.0457771 & 5 \\
\hline 0.1912 & 0.015259 & 5 \\
\hline 0.1913 & 0.015259 & 5 \\
\hline 0.1915 & 0 & 5 \\
\hline 0.1917 & 0.015259 & 5 \\
\hline 0.1918 & 0 & 5 \\
\hline 0.192 & 0 & 5 \\
\hline 0.1922 & 0.015259 & 5 \\
\hline 0.1923 & 0.015259 & 5 \\
\hline 0.1925 & 0 & 5 \\
\hline 0.1927 & 0 & 5 \\
\hline
\end{tabular}

\begin{tabular}{|c|c|c|}
\hline 0.1928 & 0 & 5 \\
\hline 0.193 & 0 & 5 \\
\hline 0.1932 & 0 & 5 \\
\hline 0.1933 & 0.015259 & 5 \\
\hline 0.1935 & 0.015259 & 5 \\
\hline 0.1937 & 0 & 5 \\
\hline 0.1938 & 0.015259 & 5 \\
\hline 0.194 & 0.015259 & 5 \\
\hline 0.1942 & 0.015259 & 5 \\
\hline 0.1943 & 0.0457771 & 5 \\
\hline 0.1945 & 0 & 5 \\
\hline 0.1947 & 0.030518 & 5 \\
\hline 0.1948 & 0 & 5 \\
\hline 0.195 & 0 & 5 \\
\hline 0.1952 & 0 & 5 \\
\hline 0.1953 & 0 & 5 \\
\hline 0.1955 & 0.015259 & 5 \\
\hline 0.1957 & 0.015259 & 5 \\
\hline 0.1958 & 0.015259 & 5 \\
\hline 0.196 & 0.015259 & 5 \\
\hline 0.1962 & 0.015259 & 5 \\
\hline 0.1963 & 0.015259 & 5 \\
\hline 0.1965 & 0 & 5 \\
\hline 0.1967 & 0.015259 & 5 \\
\hline 0.1968 & 0 & 5 \\
\hline 0.197 & 0 & 5 \\
\hline 0.1972 & 0 & 5 \\
\hline 0.1973 & 0 & 5 \\
\hline 0.1975 & 0 & 5 \\
\hline 0.1977 & 0.015259 & 5 \\
\hline 0.1978 & 0.015259 & 5 \\
\hline 0.198 & 0 & 5 \\
\hline 0.1982 & 0.015259 & 5 \\
\hline 0.1983 & 0.015259 & 5 \\
\hline 0.1985 & 0.030518 & 5 \\
\hline 0.1987 & 0 & 5 \\
\hline 0.1988 & 0 & 5 \\
\hline 0.199 & 0 & 5 \\
\hline 0.1992 & 0.015259 & 5 \\
\hline 0.1993 & 0 & 5 \\
\hline 0.1995 & 0.015259 & 5 \\
\hline
\end{tabular}




\begin{tabular}{|c|c|c|}
\hline 0.1997 & 0 & 5 \\
\hline 0.1998 & 0 & 5 \\
\hline 0.2 & 0.015259 & 5 \\
\hline 0.2002 & 0 & 5 \\
\hline 0.2003 & 0.030518 & 5 \\
\hline 0.2005 & 0 & 5 \\
\hline 0.2007 & 0.015259 & 5 \\
\hline 0.2008 & 0.030518 & 5 \\
\hline 0.201 & 0.015259 & 5 \\
\hline 0.2012 & 0 & 5 \\
\hline 0.2013 & 0 & 5 \\
\hline 0.2015 & 0.015259 & 5 \\
\hline 0.2017 & 0 & 5 \\
\hline 0.2018 & 0 & 5 \\
\hline 0.202 & 0 & 5 \\
\hline 0.2022 & 0.015259 & 5 \\
\hline 0.2023 & 0 & 5 \\
\hline 0.2025 & 0.015259 & 5 \\
\hline 0.2027 & 0 & 5 \\
\hline 0.2028 & 0.015259 & 5 \\
\hline 0.203 & 0.015259 & 5 \\
\hline 0.2032 & 0.015259 & 5 \\
\hline 0.2033 & 0.015259 & 5 \\
\hline 0.2035 & 0.015259 & 5 \\
\hline 0.2037 & 0.015259 & 5 \\
\hline 0.2038 & 0.015259 & 5 \\
\hline 0.204 & 0.030518 & 5 \\
\hline 0.2042 & 0.015259 & 5 \\
\hline 0.2043 & 0 & 5 \\
\hline 0.2045 & 0 & 5 \\
\hline 0.2047 & 0 & 5 \\
\hline 0.2048 & 0 & 5 \\
\hline 0.205 & 0.015259 & 5 \\
\hline 0.2052 & 0 & 5 \\
\hline 0.2053 & 0.015259 & 5 \\
\hline 0.2055 & 0 & 5 \\
\hline 0.2057 & 0.015259 & 5 \\
\hline 0.2058 & 0.0457771 & 5 \\
\hline 0.206 & 0 & 5 \\
\hline 0.2062 & 0 & 5 \\
\hline 0.2063 & 0 & 5 \\
\hline
\end{tabular}

\begin{tabular}{|c|c|c|}
\hline 0.2065 & 0 & 5 \\
\hline 0.2067 & 0.015259 & 5 \\
\hline 0.2068 & 0.015259 & 5 \\
\hline 0.207 & 0 & 5 \\
\hline 0.2072 & 0.030518 & 5 \\
\hline 0.2073 & 0 & 5 \\
\hline 0.2075 & 0 & 5 \\
\hline 0.2077 & 0 & 5 \\
\hline 0.2078 & 0.015259 & 5 \\
\hline 0.208 & 0.015259 & 5 \\
\hline 0.2082 & 0 & 5 \\
\hline 0.2083 & 0.030518 & 5 \\
\hline 0.2085 & 0 & 5 \\
\hline 0.2087 & 0 & 5 \\
\hline 0.2088 & 0 & 5 \\
\hline 0.209 & 0 & 5 \\
\hline 0.2092 & 0.015259 & 5 \\
\hline 0.2093 & 0 & 5 \\
\hline 0.2095 & 0.030518 & 5 \\
\hline 0.2097 & 0 & 5 \\
\hline 0.2098 & 0.015259 & 5 \\
\hline 0.21 & 0 & 5 \\
\hline 0.2102 & 0 & 5 \\
\hline 0.2103 & 0.015259 & 5 \\
\hline 0.2105 & 0.015259 & 5 \\
\hline 0.2107 & 0 & 5 \\
\hline 0.2108 & 0.015259 & 5 \\
\hline 0.211 & 0.015259 & 5 \\
\hline 0.2112 & 0 & 5 \\
\hline 0.2113 & 0 & 5 \\
\hline 0.2115 & 0 & 5 \\
\hline 0.2117 & 0 & 5 \\
\hline 0.2118 & 0.030518 & 5 \\
\hline 0.212 & 0 & 5 \\
\hline 0.2122 & 0.015259 & 5 \\
\hline 0.2123 & 0.015259 & 5 \\
\hline 0.2125 & 0 & 5 \\
\hline 0.2127 & 0 & 5 \\
\hline 0.2128 & 0 & 5 \\
\hline 0.213 & 0 & 5 \\
\hline 0.2132 & 0.015259 & 5 \\
\hline
\end{tabular}




\begin{tabular}{|c|c|c|}
\hline 0.2133 & 0 & 5 \\
\hline 0.2135 & 0 & 5 \\
\hline 0.2137 & 0 & 5 \\
\hline 0.2138 & 0 & 5 \\
\hline 0.214 & 0 & 5 \\
\hline 0.2142 & 0.015259 & 5 \\
\hline 0.2143 & 0.015259 & 5 \\
\hline 0.2145 & 0 & 5 \\
\hline 0.2147 & 0.030518 & 5 \\
\hline 0.2148 & 0 & 5 \\
\hline 0.215 & 0.015259 & 5 \\
\hline 0.2152 & 0 & 5 \\
\hline 0.2153 & 0 & 5 \\
\hline 0.2155 & 0.015259 & 5 \\
\hline 0.2157 & 0 & 5 \\
\hline 0.2158 & 0 & 5 \\
\hline 0.216 & 0 & 5 \\
\hline 0.2162 & 0.015259 & 5 \\
\hline 0.2163 & 0 & 5 \\
\hline 0.2165 & 0 & 5 \\
\hline 0.2167 & 0.030518 & 5 \\
\hline 0.2168 & 0 & 5 \\
\hline 0.217 & 0 & 5 \\
\hline 0.2172 & 0.030518 & 5 \\
\hline 0.2173 & 0 & 5 \\
\hline 0.2175 & 0 & 5 \\
\hline 0.2177 & 0.015259 & 5 \\
\hline 0.2178 & 0 & 5 \\
\hline 0.218 & 0 & 5 \\
\hline 0.2182 & 0.015259 & 5 \\
\hline 0.2183 & 0.030518 & 5 \\
\hline 0.2185 & 0 & 5 \\
\hline 0.2187 & 0 & 5 \\
\hline 0.2188 & 0 & 5 \\
\hline 0.219 & 0.015259 & 5 \\
\hline 0.2192 & 0 & 5 \\
\hline 0.2193 & 0.015259 & 5 \\
\hline 0.2195 & 0 & 5 \\
\hline 0.2197 & 0 & 5 \\
\hline 0.2198 & 0.015259 & 5 \\
\hline 0.22 & 0.015259 & 5 \\
\hline
\end{tabular}

\begin{tabular}{|c|c|c|}
\hline 0.2202 & 0 & 5 \\
\hline 0.2203 & 0.015259 & 5 \\
\hline 0.2205 & 0 & 5 \\
\hline 0.2207 & 0.030518 & 5 \\
\hline 0.2208 & 0 & 5 \\
\hline 0.221 & 0.030518 & 5 \\
\hline 0.2212 & 0.015259 & 5 \\
\hline 0.2213 & 0.030518 & 5 \\
\hline 0.2215 & 0.030518 & 5 \\
\hline 0.2217 & 0 & 5 \\
\hline 0.2218 & 0.015259 & 5 \\
\hline 0.222 & 0 & 5 \\
\hline 0.2222 & 0.015259 & 5 \\
\hline 0.2223 & 0.030518 & 5 \\
\hline 0.2225 & 0 & 5 \\
\hline 0.2227 & 0 & 5 \\
\hline 0.2228 & 0.015259 & 5 \\
\hline 0.223 & 0 & 5 \\
\hline 0.2232 & 0.030518 & 5 \\
\hline 0.2233 & 0.015259 & 5 \\
\hline 0.2235 & 0.015259 & 5 \\
\hline 0.2237 & 0 & 5 \\
\hline 0.2238 & 0.015259 & 5 \\
\hline 0.224 & 0.015259 & 5 \\
\hline 0.2242 & 0.015259 & 5 \\
\hline 0.2243 & 0 & 5 \\
\hline 0.2245 & 0.0457771 & 5 \\
\hline 0.2247 & 0 & 5 \\
\hline 0.2248 & 0.015259 & 5 \\
\hline 0.225 & 0 & 5 \\
\hline 0.2252 & 0 & 5 \\
\hline 0.2253 & 0 & 5 \\
\hline 0.2255 & 0.015259 & 5 \\
\hline 0.2257 & 0 & 5 \\
\hline 0.2258 & 0 & 5 \\
\hline 0.226 & 0 & 5 \\
\hline 0.2262 & 0 & 5 \\
\hline 0.2263 & 0 & 5 \\
\hline 0.2265 & 0 & 5 \\
\hline 0.2267 & 0.015259 & 5 \\
\hline 0.2268 & 0 & 5 \\
\hline
\end{tabular}




\begin{tabular}{|c|c|c|}
\hline 0.227 & 0 & 5 \\
\hline 0.2272 & 0.015259 & 5 \\
\hline 0.2273 & 0 & 5 \\
\hline 0.2275 & 0.030518 & 5 \\
\hline 0.2277 & 0.015259 & 5 \\
\hline 0.2278 & 0 & 5 \\
\hline 0.228 & 0.015259 & 5 \\
\hline 0.2282 & 0.015259 & 5 \\
\hline 0.2283 & 0 & 5 \\
\hline 0.2285 & 0 & 5 \\
\hline 0.2287 & 0 & 5 \\
\hline 0.2288 & 0 & 5 \\
\hline 0.229 & 0 & 5 \\
\hline 0.2292 & 0 & 5 \\
\hline 0.2293 & 0.015259 & 5 \\
\hline 0.2295 & 0 & 5 \\
\hline 0.2297 & 0 & 5 \\
\hline 0.2298 & 0 & 5 \\
\hline 0.23 & 0 & 5 \\
\hline 0.2302 & 0 & 5 \\
\hline 0.2303 & 0.015259 & 5 \\
\hline 0.2305 & 0 & 5 \\
\hline
\end{tabular}

\begin{tabular}{|c|c|c|}
\hline 0.2307 & 0 & 5 \\
\hline 0.2308 & 0.015259 & 5 \\
\hline 0.231 & 0.015259 & 5 \\
\hline 0.2312 & 0 & 5 \\
\hline 0.2313 & 0 & 5 \\
\hline 0.2315 & 0 & 5 \\
\hline 0.2317 & 0 & 5 \\
\hline 0.2318 & 0 & 5 \\
\hline 0.232 & 0 & 5 \\
\hline 0.2322 & 0.030518 & 5 \\
\hline 0.2323 & 0 & 5 \\
\hline 0.2325 & 0 & 5 \\
\hline 0.2327 & 0 & 5 \\
\hline 0.2328 & 0 & 5 \\
\hline 0.233 & 0 & 5 \\
\hline 0.2332 & 0.015259 & 5 \\
\hline 0.2333 & 0 & 5 \\
\hline 0.2335 & 0 & 5 \\
\hline 0.2502 & 0 & 5 \\
\hline 0.2668 & 0 & 5 \\
\hline 0.2835 & 0 & 5 \\
\hline 0.3002 & 0 & 5 \\
\hline
\end{tabular}




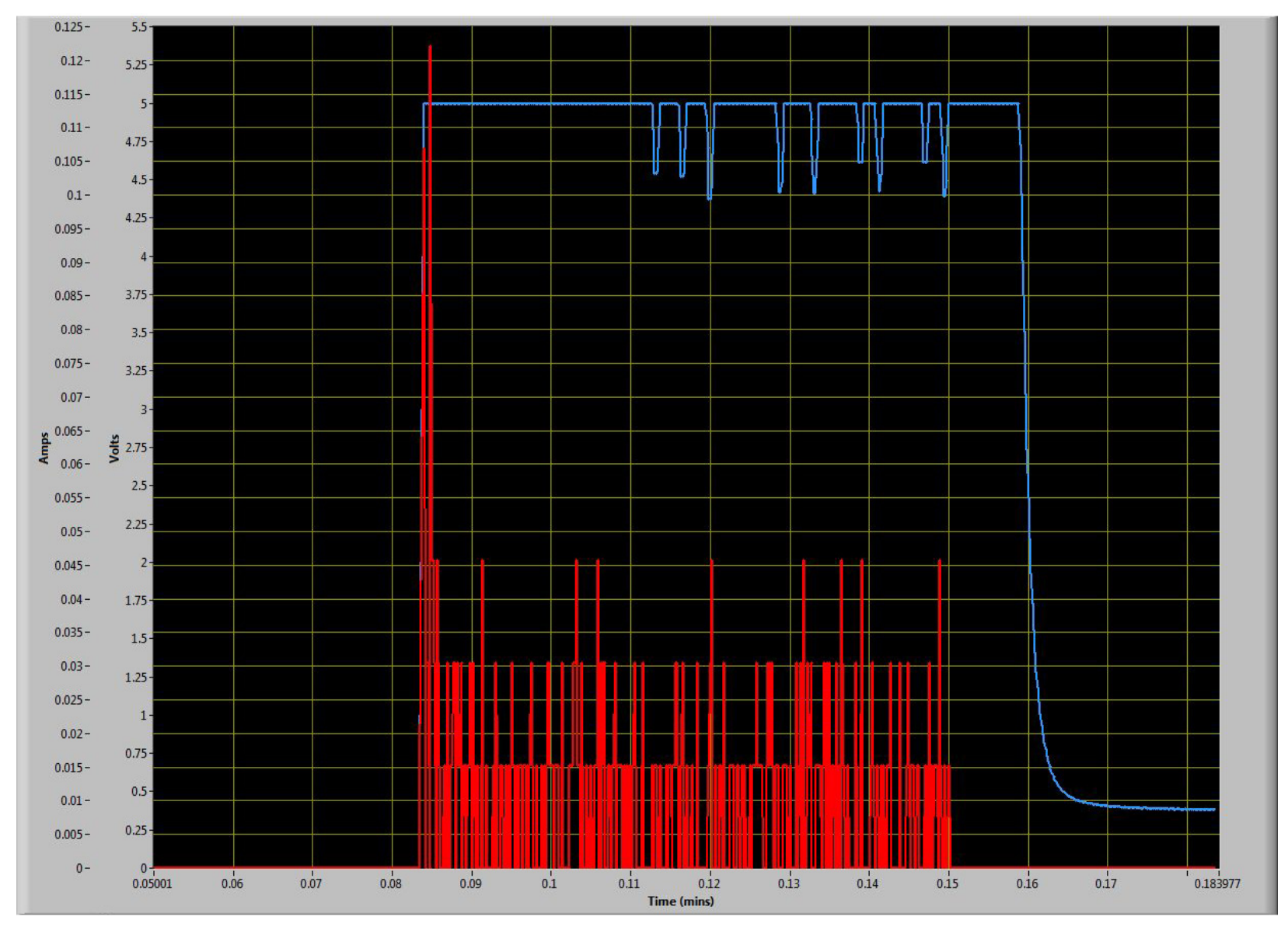

\begin{tabular}{|r|r|r|}
\hline $\begin{array}{l}\text { Time } \\
\text { (minuets) }\end{array}$ & Amps & \multicolumn{1}{l|}{ Volts } \\
\hline 0.0502 & 0 & 0 \\
\hline 0.0503 & 0 & 0 \\
\hline 0.0505 & 0 & 0 \\
\hline 0.0507 & 0 & 0 \\
\hline 0.0508 & 0 & 0 \\
\hline 0.051 & 0 & 0 \\
\hline 0.0512 & 0 & 0 \\
\hline 0.0513 & 0 & 0.00015259 \\
\hline 0.0515 & 0 & 0.00015259 \\
\hline 0.0517 & 0 & $7.63 \mathrm{E}-05$ \\
\hline 0.0518 & 0 & $7.63 \mathrm{E}-05$ \\
\hline 0.052 & 0 & $7.63 \mathrm{E}-05$ \\
\hline 0.0522 & 0 & $7.63 \mathrm{E}-05$ \\
\hline 0.0523 & 0 & 0.00015259 \\
\hline 0.0525 & 0 & 0.00022889 \\
\hline 0.0527 & 0 & 0.00015259 \\
\hline 0.0528 & 0 & 0.00015259 \\
\hline
\end{tabular}

\begin{tabular}{|r|r|r|}
\hline 0.053 & 0 & 0.00015259 \\
\hline 0.0532 & 0 & $7.63 \mathrm{E}-05$ \\
\hline 0.0533 & 0 & $7.63 \mathrm{E}-05$ \\
\hline 0.0535 & 0 & $7.63 \mathrm{E}-05$ \\
\hline 0.0537 & 0 & 0 \\
\hline 0.0538 & 0 & 0.00015259 \\
\hline 0.054 & 0 & 0.00015259 \\
\hline 0.0542 & 0 & 0.00015259 \\
\hline 0.0543 & 0 & 0.00015259 \\
\hline 0.0545 & 0 & 0 \\
\hline 0.0547 & 0 & 0 \\
\hline 0.0548 & 0 & 0 \\
\hline 0.055 & 0 & $7.63 \mathrm{E}-05$ \\
\hline 0.0552 & 0 & $7.63 \mathrm{E}-05$ \\
\hline 0.0553 & 0 & $7.63 \mathrm{E}-05$ \\
\hline 0.0555 & 0 & 0 \\
\hline 0.0557 & 0 & $7.63 \mathrm{E}-05$ \\
\hline 0.0558 & 0 & $7.63 \mathrm{E}-05$ \\
\hline 0.056 & 0 & 0.00015259 \\
\hline
\end{tabular}




\begin{tabular}{|c|c|c|}
\hline 0.0562 & 0 & 0.00015259 \\
\hline 0.0563 & 0 & 7.63E-05 \\
\hline 0.0565 & 0 & 7.63E-05 \\
\hline 0.0567 & 0 & 0 \\
\hline 0.0568 & 0 & 0 \\
\hline 0.057 & 0 & 0 \\
\hline 0.0572 & 0 & 0 \\
\hline 0.0573 & 0 & $7.63 \mathrm{E}-05$ \\
\hline 0.0575 & 0 & $7.63 \mathrm{E}-05$ \\
\hline 0.0577 & 0 & 7.63E-05 \\
\hline 0.0578 & 0 & 7.63E-05 \\
\hline 0.058 & 0 & 0 \\
\hline 0.0582 & 0 & 7.63E-05 \\
\hline 0.0583 & 0 & 7.63E-05 \\
\hline 0.0585 & 0 & 0 \\
\hline 0.0587 & 0 & 0 \\
\hline 0.0588 & 0 & 0 \\
\hline 0.059 & 0 & 0 \\
\hline 0.0592 & 0 & 7.63E-05 \\
\hline 0.0593 & 0 & 7.63E-05 \\
\hline 0.0595 & 0 & 7.63E-05 \\
\hline 0.0597 & 0 & 0 \\
\hline 0.0598 & 0 & 0 \\
\hline 0.06 & 0 & 0 \\
\hline 0.0602 & 0 & 0 \\
\hline 0.0603 & 0 & 0 \\
\hline 0.0605 & 0 & 0 \\
\hline 0.0607 & 0 & 0 \\
\hline 0.0608 & 0 & 7.63E-05 \\
\hline 0.061 & 0 & 7.63E-05 \\
\hline 0.0612 & 0 & $7.63 \mathrm{E}-05$ \\
\hline 0.0613 & 0 & 7.63E-05 \\
\hline 0.0615 & 0 & 0 \\
\hline 0.0617 & 0 & 0 \\
\hline 0.0618 & 0 & 7.63E-05 \\
\hline 0.062 & 0 & 7.63E-05 \\
\hline 0.0622 & 0 & 7.63E-05 \\
\hline 0.0623 & 0 & 7.63E-05 \\
\hline 0.0625 & 0 & 0 \\
\hline 0.0627 & 0 & 0 \\
\hline 0.0628 & 0 & 0 \\
\hline
\end{tabular}

\begin{tabular}{|c|c|c|}
\hline 0.063 & 0 & 0 \\
\hline 0.0632 & 0 & 0 \\
\hline 0.0633 & 0 & 0 \\
\hline 0.0635 & 0 & 0 \\
\hline 0.0637 & 0 & 7.63E-05 \\
\hline 0.0638 & 0 & 0.00015259 \\
\hline 0.064 & 0 & 0.00015259 \\
\hline 0.0642 & 0 & 0.00015259 \\
\hline 0.0643 & 0 & 0 \\
\hline 0.0645 & 0 & 0 \\
\hline 0.0647 & 0 & 0 \\
\hline 0.0648 & 0 & 0 \\
\hline 0.065 & 0 & 7.63E-05 \\
\hline 0.0652 & 0 & 0 \\
\hline 0.0653 & 0 & 0 \\
\hline 0.0655 & 0 & 0 \\
\hline 0.0657 & 0 & 0 \\
\hline 0.0658 & 0 & 0 \\
\hline 0.066 & 0 & $7.63 \mathrm{E}-05$ \\
\hline 0.0662 & 0 & 7.63E-05 \\
\hline 0.0663 & 0 & 7.63E-05 \\
\hline 0.0665 & 0 & 7.63E-05 \\
\hline 0.0667 & 0 & $7.63 \mathrm{E}-05$ \\
\hline 0.0668 & 0 & 7.63E-05 \\
\hline 0.067 & 0 & 0.00015259 \\
\hline 0.0672 & 0 & $7.63 \mathrm{E}-05$ \\
\hline 0.0673 & 0 & 7.63E-05 \\
\hline 0.0675 & 0 & 7.63E-05 \\
\hline 0.0677 & 0 & 0 \\
\hline 0.0678 & 0 & 0 \\
\hline 0.068 & 0 & 0 \\
\hline 0.0682 & 0 & 0 \\
\hline 0.0683 & 0 & 7.63E-05 \\
\hline 0.0685 & 0 & 7.63E-05 \\
\hline 0.0687 & 0 & 7.63E-05 \\
\hline 0.0688 & 0 & 0 \\
\hline 0.069 & 0 & $7.63 \mathrm{E}-05$ \\
\hline 0.0692 & 0 & 7.63E-05 \\
\hline 0.0693 & 0 & 7.63E-05 \\
\hline 0.0695 & 0 & 0.00015259 \\
\hline 0.0697 & 0 & $7.63 \mathrm{E}-05$ \\
\hline
\end{tabular}




\begin{tabular}{|c|c|c|}
\hline 0.0698 & 0 & 7.63E-05 \\
\hline 0.07 & 0 & 7.63E-05 \\
\hline 0.0702 & 0 & $7.63 \mathrm{E}-05$ \\
\hline 0.0703 & 0 & 0 \\
\hline 0.0705 & 0 & 0 \\
\hline 0.0707 & 0 & 0 \\
\hline 0.0708 & 0 & 0 \\
\hline 0.071 & 0 & 0 \\
\hline 0.0712 & 0 & 0 \\
\hline 0.0713 & 0 & 0 \\
\hline 0.0715 & 0 & 0 \\
\hline 0.0717 & 0 & 7.63E-05 \\
\hline 0.0718 & 0 & 7.63E-05 \\
\hline 0.072 & 0 & 0 \\
\hline 0.0722 & 0 & 0 \\
\hline 0.0723 & 0 & 0 \\
\hline 0.0725 & 0 & 0 \\
\hline 0.0727 & 0 & 0 \\
\hline 0.0728 & 0 & 0 \\
\hline 0.073 & 0 & 0 \\
\hline 0.0732 & 0 & 0 \\
\hline 0.0733 & 0 & 0 \\
\hline 0.0735 & 0 & 0 \\
\hline 0.0737 & 0 & 0 \\
\hline 0.0738 & 0 & 0 \\
\hline 0.074 & 0 & 0 \\
\hline 0.0742 & 0 & 7.63E-05 \\
\hline 0.0743 & 0 & 7.63E-05 \\
\hline 0.0745 & 0 & 7.63E-05 \\
\hline 0.0747 & 0 & 0 \\
\hline 0.0748 & 0 & 0 \\
\hline 0.075 & 0 & 0 \\
\hline 0.0752 & 0 & 0 \\
\hline 0.0753 & 0 & 0 \\
\hline 0.0755 & 0 & 7.63E-05 \\
\hline 0.0757 & 0 & 7.63E-05 \\
\hline 0.0758 & 0 & 0.00015259 \\
\hline 0.076 & 0 & 0.00015259 \\
\hline 0.0762 & 0 & 7.63E-05 \\
\hline 0.0763 & 0 & 7.63E-05 \\
\hline 0.0765 & 0 & 0 \\
\hline
\end{tabular}

\begin{tabular}{|c|c|c|}
\hline 0.0767 & 0 & 7.63E-05 \\
\hline 0.0768 & 0 & $7.63 \mathrm{E}-05$ \\
\hline 0.077 & 0 & 7.63E-05 \\
\hline 0.0772 & 0 & $7.63 \mathrm{E}-05$ \\
\hline 0.0773 & 0 & 0 \\
\hline 0.0775 & 0 & 0 \\
\hline 0.0777 & 0 & 0 \\
\hline 0.0778 & 0 & $7.63 \mathrm{E}-05$ \\
\hline 0.078 & 0 & 7.63E-05 \\
\hline 0.0782 & 0 & 7.63E-05 \\
\hline 0.0783 & 0 & 0.00015259 \\
\hline 0.0785 & 0 & 0.00015259 \\
\hline 0.0787 & 0 & 0.00015259 \\
\hline 0.0788 & 0 & 0.00015259 \\
\hline 0.079 & 0 & 7.63E-05 \\
\hline 0.0792 & 0 & 0 \\
\hline 0.0793 & 0 & 0 \\
\hline 0.0795 & 0 & 7.63E-05 \\
\hline 0.0797 & 0 & $7.63 \mathrm{E}-05$ \\
\hline 0.0798 & 0 & 7.63E-05 \\
\hline 0.08 & 0 & 0 \\
\hline 0.0802 & 0 & 0 \\
\hline 0.0803 & 0 & 0 \\
\hline 0.0805 & 0 & 0 \\
\hline 0.0807 & 0 & 0 \\
\hline 0.0808 & 0 & 0 \\
\hline 0.081 & 0 & 0 \\
\hline 0.0812 & 0 & 0.00015259 \\
\hline 0.0813 & 0 & 0.00015259 \\
\hline 0.0815 & 0 & 0.00015259 \\
\hline 0.0817 & 0 & 0.00022889 \\
\hline 0.0818 & 0 & 7.63E-05 \\
\hline 0.082 & 0 & 0 \\
\hline 0.0822 & 0 & 0 \\
\hline 0.0823 & 0 & 0 \\
\hline 0.0825 & 0 & 0 \\
\hline 0.0827 & 0 & $7.63 \mathrm{E}-05$ \\
\hline 0.0828 & 0 & 7.63E-05 \\
\hline 0.083 & 0 & 7.63E-05 \\
\hline 0.0832 & 0 & 0.00022889 \\
\hline 0.0833 & 0 & 0.00015259 \\
\hline
\end{tabular}




\begin{tabular}{|c|c|c|}
\hline 0.084 & 0.106813 & 5 \\
\hline 0.0842 & 0 & 5 \\
\hline 0.0843 & 0.030518 & 5 \\
\hline 0.0845 & 0.030518 & 5 \\
\hline 0.0847 & 0 & 5 \\
\hline 0.0848 & 0.122072 & 5 \\
\hline 0.085 & 0.0457771 & 5 \\
\hline 0.0852 & 0.0457771 & 5 \\
\hline 0.0853 & 0.030518 & 5 \\
\hline 0.0855 & 0 & 5 \\
\hline 0.0857 & 0.0457771 & 5 \\
\hline 0.0858 & 0.030518 & 5 \\
\hline 0.086 & 0 & 5 \\
\hline 0.0862 & 0 & 5 \\
\hline 0.0863 & 0 & 5 \\
\hline 0.0865 & 0.015259 & 5 \\
\hline 0.0867 & 0 & 5 \\
\hline 0.0868 & 0 & 5 \\
\hline 0.087 & 0.030518 & 5 \\
\hline 0.0872 & 0 & 5 \\
\hline 0.0873 & 0.015259 & 5 \\
\hline 0.0875 & 0.015259 & 5 \\
\hline 0.0877 & 0.030518 & 5 \\
\hline 0.0878 & 0.030518 & 5 \\
\hline 0.088 & 0 & 5 \\
\hline 0.0882 & 0.030518 & 5 \\
\hline 0.0883 & 0.015259 & 5 \\
\hline 0.0885 & 0.015259 & 5 \\
\hline 0.0887 & 0.030518 & 5 \\
\hline 0.0888 & 0 & 5 \\
\hline 0.089 & 0.015259 & 5 \\
\hline 0.0892 & 0.015259 & 5 \\
\hline 0.0893 & 0 & 5 \\
\hline 0.0895 & 0.015259 & 5 \\
\hline 0.0897 & 0.015259 & 5 \\
\hline 0.0898 & 0.030518 & 5 \\
\hline 0.09 & 0 & 5 \\
\hline 0.0902 & 0.030518 & 5 \\
\hline 0.0903 & 0.015259 & 5 \\
\hline 0.0905 & 0 & 5 \\
\hline 0.0907 & 0.015259 & 5 \\
\hline
\end{tabular}

\begin{tabular}{|c|c|c|}
\hline 0.0908 & 0 & 5 \\
\hline 0.091 & 0 & 5 \\
\hline 0.0912 & 0.015259 & 5 \\
\hline 0.0913 & 0.0457771 & 5 \\
\hline 0.0915 & 0 & 5 \\
\hline 0.0917 & 0 & 5 \\
\hline 0.0918 & 0.015259 & 5 \\
\hline 0.092 & 0 & 5 \\
\hline 0.0922 & 0 & 5 \\
\hline 0.0923 & 0 & 5 \\
\hline 0.0925 & 0 & 5 \\
\hline 0.0927 & 0.015259 & 5 \\
\hline 0.0928 & 0 & 5 \\
\hline 0.093 & 0.030518 & 5 \\
\hline 0.0932 & 0.015259 & 5 \\
\hline 0.0933 & 0 & 5 \\
\hline 0.0935 & 0 & 5 \\
\hline 0.0937 & 0.015259 & 5 \\
\hline 0.0938 & 0.015259 & 5 \\
\hline 0.094 & 0 & 5 \\
\hline 0.0942 & 0 & 5 \\
\hline 0.0943 & 0.015259 & 5 \\
\hline 0.0945 & 0 & 5 \\
\hline 0.0947 & 0.015259 & 5 \\
\hline 0.0948 & 0 & 5 \\
\hline 0.095 & 0.030518 & 5 \\
\hline 0.0952 & 0.015259 & 5 \\
\hline 0.0953 & 0.015259 & 5 \\
\hline 0.0955 & 0 & 5 \\
\hline 0.0957 & 0.015259 & 5 \\
\hline 0.0958 & 0 & 5 \\
\hline 0.096 & 0.015259 & 5 \\
\hline 0.0962 & 0.015259 & 5 \\
\hline 0.0963 & 0 & 5 \\
\hline 0.0965 & 0.015259 & 5 \\
\hline 0.0967 & 0.015259 & 5 \\
\hline 0.0968 & 0 & 5 \\
\hline 0.097 & 0.015259 & 5 \\
\hline 0.0972 & 0 & 5 \\
\hline 0.0973 & 0.015259 & 5 \\
\hline 0.0975 & 0.030518 & 5 \\
\hline
\end{tabular}




\begin{tabular}{|c|c|c|}
\hline 0.0977 & 0 & 5 \\
\hline 0.0978 & 0 & 5 \\
\hline 0.098 & 0 & 5 \\
\hline 0.0982 & 0.015259 & 5 \\
\hline 0.0983 & 0 & 5 \\
\hline 0.0985 & 0 & 5 \\
\hline 0.0987 & 0 & 5 \\
\hline 0.0988 & 0.015259 & 5 \\
\hline 0.099 & 0 & 5 \\
\hline 0.0992 & 0.015259 & 5 \\
\hline 0.0993 & 0 & 5 \\
\hline 0.0995 & 0.030518 & 5 \\
\hline 0.0997 & 0.030518 & 5 \\
\hline 0.0998 & 0.015259 & 5 \\
\hline 0.1 & 0.015259 & 5 \\
\hline 0.1002 & 0.015259 & 5 \\
\hline 0.1003 & 0 & 5 \\
\hline 0.1005 & 0.015259 & 5 \\
\hline 0.1007 & 0.015259 & 5 \\
\hline 0.1008 & 0.015259 & 5 \\
\hline 0.101 & 0 & 5 \\
\hline 0.1012 & 0 & 5 \\
\hline 0.1013 & 0.030518 & 5 \\
\hline 0.1015 & 0 & 5 \\
\hline 0.1017 & 0 & 5 \\
\hline 0.1018 & 0 & 5 \\
\hline 0.102 & 0 & 5 \\
\hline 0.1022 & 0 & 5 \\
\hline 0.1023 & 0.015259 & 5 \\
\hline 0.1025 & 0.015259 & 5 \\
\hline 0.1027 & 0.015259 & 5 \\
\hline 0.1028 & 0.030518 & 5 \\
\hline 0.103 & 0.030518 & 5 \\
\hline 0.1032 & 0.0457771 & 5 \\
\hline 0.1033 & 0.015259 & 5 \\
\hline 0.1035 & 0.015259 & 5 \\
\hline 0.1037 & 0 & 5 \\
\hline 0.1038 & 0.030518 & 5 \\
\hline 0.104 & 0 & 5 \\
\hline 0.1042 & 0 & 5 \\
\hline 0.1043 & 0 & 5 \\
\hline
\end{tabular}

\begin{tabular}{|c|c|c|}
\hline 0.1045 & 0.015259 & 5 \\
\hline 0.1047 & 0 & 5 \\
\hline 0.1048 & 0 & 5 \\
\hline 0.105 & 0.015259 & 5 \\
\hline 0.1052 & 0 & 5 \\
\hline 0.1053 & 0 & 5 \\
\hline 0.1055 & 0.015259 & 5 \\
\hline 0.1057 & 0.015259 & 5 \\
\hline 0.1058 & 0.0457771 & 5 \\
\hline 0.106 & 0 & 5 \\
\hline 0.1062 & 0.030518 & 5 \\
\hline 0.1063 & 0 & 5 \\
\hline 0.1065 & 0.030518 & 5 \\
\hline 0.1067 & 0.030518 & 5 \\
\hline 0.1068 & 0 & 5 \\
\hline 0.107 & 0 & 5 \\
\hline 0.1072 & 0.015259 & 5 \\
\hline 0.1073 & 0.015259 & 5 \\
\hline 0.1075 & 0 & 5 \\
\hline 0.1077 & 0.015259 & 5 \\
\hline 0.1078 & 0.015259 & 5 \\
\hline 0.108 & 0.030518 & 5 \\
\hline 0.1082 & 0 & 5 \\
\hline 0.1083 & 0.015259 & 5 \\
\hline 0.1085 & 0.015259 & 5 \\
\hline 0.1087 & 0.015259 & 5 \\
\hline 0.1088 & 0.015259 & 5 \\
\hline 0.109 & 0 & 5 \\
\hline 0.1092 & 0.015259 & 5 \\
\hline 0.1093 & 0 & 5 \\
\hline 0.1095 & 0.015259 & 5 \\
\hline 0.1097 & 0 & 5 \\
\hline 0.1098 & 0.015259 & 5 \\
\hline 0.11 & 0 & 5 \\
\hline 0.1102 & 0 & 5 \\
\hline 0.1103 & 0.015259 & 5 \\
\hline 0.1105 & 0.030518 & 5 \\
\hline 0.1107 & 0 & 5 \\
\hline 0.1108 & 0 & 5 \\
\hline 0.111 & 0 & 5 \\
\hline 0.1112 & 0 & 5 \\
\hline
\end{tabular}




\begin{tabular}{|c|c|c|}
\hline 0.1113 & 0 & 5 \\
\hline 0.1115 & 0.030518 & 5 \\
\hline 0.1117 & 0 & 5 \\
\hline 0.1118 & 0 & 5 \\
\hline 0.112 & 0 & 5 \\
\hline 0.1122 & 0 & 5 \\
\hline 0.1123 & 0 & 5 \\
\hline 0.1125 & 0 & 5 \\
\hline 0.1127 & 0.015259 & 4.98856 \\
\hline 0.1128 & 0 & 4.8294 \\
\hline 0.113 & 0.015259 & 4.54078 \\
\hline 0.1132 & 0.015259 & 4.54078 \\
\hline 0.1133 & 0 & 4.55215 \\
\hline 0.1135 & 0 & 4.7113 \\
\hline 0.1137 & 0.015259 & 5 \\
\hline 0.1138 & 0 & 5 \\
\hline 0.114 & 0 & 5 \\
\hline 0.1142 & 0 & 5 \\
\hline 0.1143 & 0 & 5 \\
\hline 0.1145 & 0.015259 & 5 \\
\hline 0.1147 & 0 & 5 \\
\hline 0.1148 & 0.015259 & 5 \\
\hline 0.115 & 0.015259 & 5 \\
\hline 0.1152 & 0 & 5 \\
\hline 0.1153 & 0.015259 & 5 \\
\hline 0.1155 & 0.015259 & 5 \\
\hline 0.1157 & 0.030518 & 5 \\
\hline 0.1158 & 0.030518 & 5 \\
\hline 0.116 & 0 & 4.98352 \\
\hline 0.1162 & 0 & 4.81857 \\
\hline 0.1163 & 0.015259 & 4.523 \\
\hline 0.1165 & 0.030518 & 4.523 \\
\hline 0.1167 & 0 & 4.53941 \\
\hline 0.1168 & 0 & 4.70436 \\
\hline 0.117 & 0.015259 & 5 \\
\hline 0.1172 & 0 & 5 \\
\hline 0.1173 & 0 & 5 \\
\hline 0.1175 & 0 & 5 \\
\hline 0.1177 & 0.015259 & 5 \\
\hline 0.1178 & 0 & 5 \\
\hline 0.118 & 0 & 5 \\
\hline
\end{tabular}

\begin{tabular}{|c|c|c|}
\hline 0.1182 & 0 & 5 \\
\hline 0.1183 & 0.030518 & 5 \\
\hline 0.1185 & 0 & 5 \\
\hline 0.1187 & 0 & 5 \\
\hline 0.1188 & 0 & 5 \\
\hline 0.119 & 0 & 5 \\
\hline 0.1192 & 0 & 5 \\
\hline 0.1193 & 0 & 5 \\
\hline 0.1195 & 0 & 4.92622 \\
\hline 0.1197 & 0.015259 & 4.70886 \\
\hline 0.1198 & 0.015259 & 4.37469 \\
\hline 0.12 & 0.030518 & 4.37469 \\
\hline 0.1202 & 0.0457771 & 4.44839 \\
\hline 0.1203 & 0 & 4.66583 \\
\hline 0.1205 & 0 & 5 \\
\hline 0.1207 & 0.015259 & 5 \\
\hline 0.1208 & 0 & 5 \\
\hline 0.121 & 0 & 5 \\
\hline 0.1212 & 0.015259 & 5 \\
\hline 0.1213 & 0.015259 & 5 \\
\hline 0.1215 & 0 & 5 \\
\hline 0.1217 & 0.030518 & 5 \\
\hline 0.1218 & 0 & 5 \\
\hline 0.122 & 0 & 5 \\
\hline 0.1222 & 0 & 5 \\
\hline 0.1223 & 0 & 5 \\
\hline 0.1225 & 0.015259 & 5 \\
\hline 0.1227 & 0.015259 & 5 \\
\hline 0.1228 & 0.015259 & 5 \\
\hline 0.123 & 0 & 5 \\
\hline 0.1232 & 0 & 5 \\
\hline 0.1233 & 0.015259 & 5 \\
\hline 0.1235 & 0.015259 & 5 \\
\hline 0.1237 & 0 & 5 \\
\hline 0.1238 & 0 & 5 \\
\hline 0.124 & 0.015259 & 5 \\
\hline 0.1242 & 0 & 5 \\
\hline 0.1243 & 0.015259 & 5 \\
\hline 0.1245 & 0 & 5 \\
\hline 0.1247 & 0 & 5 \\
\hline 0.1248 & 0 & 5 \\
\hline
\end{tabular}




\begin{tabular}{|c|c|c|}
\hline 0.125 & 0.015259 & 5 \\
\hline 0.1252 & 0 & 5 \\
\hline 0.1253 & 0.015259 & 5 \\
\hline 0.1255 & 0.015259 & 5 \\
\hline 0.1257 & 0.015259 & 5 \\
\hline 0.1258 & 0.030518 & 5 \\
\hline 0.126 & 0.015259 & 5 \\
\hline 0.1262 & 0.015259 & 5 \\
\hline 0.1263 & 0.015259 & 5 \\
\hline 0.1265 & 0.015259 & 5 \\
\hline 0.1267 & 0 & 5 \\
\hline 0.1268 & 0 & 5 \\
\hline 0.127 & 0 & 5 \\
\hline 0.1272 & 0.030518 & 5 \\
\hline 0.1273 & 0.015259 & 5 \\
\hline 0.1275 & 0.030518 & 5 \\
\hline 0.1277 & 0.015259 & 5 \\
\hline 0.1278 & 0.030518 & 5 \\
\hline 0.128 & 0 & 5 \\
\hline 0.1282 & 0 & 5 \\
\hline 0.1283 & 0.015259 & 4.93935 \\
\hline 0.1285 & 0.015259 & 4.73907 \\
\hline 0.1287 & 0 & 4.41817 \\
\hline 0.1288 & 0 & 4.41817 \\
\hline 0.129 & 0 & 4.47883 \\
\hline 0.1292 & 0.015259 & 4.6791 \\
\hline 0.1293 & 0.015259 & 5 \\
\hline 0.1295 & 0.015259 & 5 \\
\hline 0.1297 & 0 & 5 \\
\hline 0.1298 & 0 & 5 \\
\hline 0.13 & 0.015259 & 5 \\
\hline 0.1302 & 0 & 5 \\
\hline 0.1303 & 0 & 5 \\
\hline 0.1305 & 0 & 5 \\
\hline 0.1307 & 0 & 5 \\
\hline 0.1308 & 0.030518 & 5 \\
\hline 0.131 & 0 & 5 \\
\hline 0.1312 & 0.015259 & 5 \\
\hline 0.1313 & 0.030518 & 5 \\
\hline 0.1315 & 0 & 5 \\
\hline 0.1317 & 0.0457771 & 5 \\
\hline
\end{tabular}

\begin{tabular}{|c|c|c|}
\hline 0.1318 & 0 & 5 \\
\hline 0.132 & 0 & 5 \\
\hline 0.1322 & 0.015259 & 5 \\
\hline 0.1323 & 0.030518 & 5 \\
\hline 0.1325 & 0.015259 & 5 \\
\hline 0.1327 & 0.030518 & 4.89738 \\
\hline 0.1328 & 0 & 4.65812 \\
\hline 0.133 & 0 & 4.41032 \\
\hline 0.1332 & 0 & 4.41032 \\
\hline 0.1333 & 0.015259 & 4.51293 \\
\hline 0.1335 & 0.015259 & 4.75219 \\
\hline 0.1337 & 0.015259 & 5 \\
\hline 0.1338 & 0.015259 & 5 \\
\hline 0.134 & 0 & 5 \\
\hline 0.1342 & 0.015259 & 5 \\
\hline 0.1343 & 0.030518 & 5 \\
\hline 0.1345 & 0 & 5 \\
\hline 0.1347 & 0.030518 & 5 \\
\hline 0.1348 & 0 & 5 \\
\hline 0.135 & 0.030518 & 5 \\
\hline 0.1352 & 0 & 5 \\
\hline 0.1353 & 0.015259 & 5 \\
\hline 0.1355 & 0.015259 & 5 \\
\hline 0.1357 & 0 & 5 \\
\hline 0.1358 & 0.030518 & 5 \\
\hline 0.136 & 0 & 5 \\
\hline 0.1362 & 0.015259 & 5 \\
\hline 0.1363 & 0 & 5 \\
\hline 0.1365 & 0.0457771 & 5 \\
\hline 0.1367 & 0.015259 & 5 \\
\hline 0.1368 & 0.015259 & 5 \\
\hline 0.137 & 0 & 5 \\
\hline 0.1372 & 0 & 5 \\
\hline 0.1373 & 0.015259 & 5 \\
\hline 0.1375 & 0 & 5 \\
\hline 0.1377 & 0 & 5 \\
\hline 0.1378 & 0 & 5 \\
\hline 0.138 & 0 & 5 \\
\hline 0.1382 & 0 & 5 \\
\hline 0.1383 & 0.030518 & 5 \\
\hline 0.1385 & 0 & 4.87427 \\
\hline
\end{tabular}




\begin{tabular}{|c|c|c|}
\hline 0.1387 & 0 & 4.61578 \\
\hline 0.1388 & 0 & 4.61578 \\
\hline 0.139 & 0.0457771 & 4.61578 \\
\hline 0.1392 & 0 & 4.74151 \\
\hline 0.1393 & 0 & 5 \\
\hline 0.1395 & 0 & 5 \\
\hline 0.1397 & 0 & 5 \\
\hline 0.1398 & 0 & 5 \\
\hline 0.14 & 0 & 5 \\
\hline 0.1402 & 0.015259 & 5 \\
\hline 0.1403 & 0.030518 & 5 \\
\hline 0.1405 & 0.015259 & 5 \\
\hline 0.1407 & 0 & 5 \\
\hline 0.1408 & 0 & 4.89311 \\
\hline 0.141 & 0.015259 & 4.65347 \\
\hline 0.1412 & 0 & 4.42954 \\
\hline 0.1413 & 0 & 4.42954 \\
\hline 0.1415 & 0.015259 & 4.53643 \\
\hline 0.1417 & 0 & 4.776 \\
\hline 0.1418 & 0.015259 & 5 \\
\hline 0.142 & 0 & 5 \\
\hline 0.1422 & 0 & 5 \\
\hline 0.1423 & 0.015259 & 5 \\
\hline 0.1425 & 0.015259 & 5 \\
\hline 0.1427 & 0.030518 & 5 \\
\hline 0.1428 & 0 & 5 \\
\hline 0.143 & 0 & 5 \\
\hline 0.1432 & 0 & 5 \\
\hline 0.1433 & 0 & 5 \\
\hline 0.1435 & 0 & 5 \\
\hline 0.1437 & 0 & 5 \\
\hline 0.1438 & 0.030518 & 5 \\
\hline 0.144 & 0 & 5 \\
\hline 0.1442 & 0 & 5 \\
\hline 0.1443 & 0 & 5 \\
\hline 0.1445 & 0 & 5 \\
\hline 0.1447 & 0.015259 & 5 \\
\hline 0.1448 & 0.030518 & 5 \\
\hline 0.145 & 0.015259 & 5 \\
\hline 0.1452 & 0 & 5 \\
\hline 0.1453 & 0.015259 & 5 \\
\hline
\end{tabular}

\begin{tabular}{|c|c|c|}
\hline 0.1455 & 0.015259 & 5 \\
\hline 0.1457 & 0 & 5 \\
\hline 0.1458 & 0 & 5 \\
\hline 0.146 & 0.015259 & 5 \\
\hline 0.1462 & 0.015259 & 5 \\
\hline 0.1463 & 0 & 5 \\
\hline 0.1465 & 0 & 5 \\
\hline 0.1467 & 0 & 4.87282 \\
\hline 0.1468 & 0 & 4.617 \\
\hline 0.147 & 0.015259 & 4.617 \\
\hline 0.1472 & 0 & 4.617 \\
\hline 0.1473 & 0 & 4.74418 \\
\hline 0.1475 & 0.030518 & 5 \\
\hline 0.1477 & 0 & 5 \\
\hline 0.1478 & 0.015259 & 5 \\
\hline 0.148 & 0 & 5 \\
\hline 0.1482 & 0.015259 & 5 \\
\hline 0.1483 & 0.015259 & 5 \\
\hline 0.1485 & 0.015259 & 5 \\
\hline 0.1487 & 0 & 5 \\
\hline 0.1488 & 0.0457771 & 5 \\
\hline 0.149 & 0.015259 & 4.89975 \\
\hline 0.1492 & 0 & 4.66682 \\
\hline 0.1493 & 0 & 4.3917 \\
\hline 0.1495 & 0.015259 & 4.3917 \\
\hline 0.1497 & 0 & 4.49187 \\
\hline 0.1498 & 0 & 4.72488 \\
\hline 0.15 & 0.015259 & 5 \\
\hline 0.1502 & 0 & 5 \\
\hline 0.1503 & 0 & 5 \\
\hline 0.1505 & 0 & 5 \\
\hline 0.1507 & 0 & 5 \\
\hline 0.1508 & 0 & 5 \\
\hline 0.151 & 0 & 5 \\
\hline 0.1512 & 0 & 5 \\
\hline 0.1513 & 0 & 5 \\
\hline 0.1515 & 0 & 5 \\
\hline 0.1517 & 0 & 5 \\
\hline 0.1518 & 0 & 5 \\
\hline 0.152 & 0 & 5 \\
\hline 0.1522 & 0 & 5 \\
\hline
\end{tabular}




\begin{tabular}{|c|c|c|}
\hline 0.1523 & 0 & 5 \\
\hline 0.1525 & 0 & 5 \\
\hline 0.1527 & 0 & 5 \\
\hline 0.1528 & 0 & 5 \\
\hline 0.153 & 0 & 5 \\
\hline 0.1532 & 0 & 5 \\
\hline 0.1533 & 0 & 5 \\
\hline 0.1535 & 0 & 5 \\
\hline 0.1537 & 0 & 5 \\
\hline 0.1538 & 0 & 5 \\
\hline 0.154 & 0 & 5 \\
\hline 0.1542 & 0 & 5 \\
\hline 0.1543 & 0 & 5 \\
\hline 0.1545 & 0 & 5 \\
\hline 0.1547 & 0 & 5 \\
\hline 0.1548 & 0 & 5 \\
\hline 0.155 & 0 & 5 \\
\hline 0.1552 & 0 & 5 \\
\hline 0.1553 & 0 & 5 \\
\hline 0.1555 & 0 & 5 \\
\hline 0.1557 & 0 & 5 \\
\hline 0.1558 & 0 & 5 \\
\hline 0.156 & 0 & 5 \\
\hline 0.1562 & 0 & 5 \\
\hline 0.1563 & 0 & 5 \\
\hline 0.1565 & 0 & 5 \\
\hline 0.1567 & 0 & 5 \\
\hline 0.1568 & 0 & 5 \\
\hline 0.157 & 0 & 5 \\
\hline 0.1572 & 0 & 5 \\
\hline 0.1573 & 0 & 5 \\
\hline 0.1575 & 0 & 5 \\
\hline 0.1577 & 0 & 5 \\
\hline 0.1578 & 0 & 5 \\
\hline 0.158 & 0 & 5 \\
\hline 0.1582 & 0 & 5 \\
\hline 0.1583 & 0 & 5 \\
\hline 0.1585 & 0 & 5 \\
\hline 0.1587 & 0 & 5 \\
\hline 0.1588 & 0 & 4.93309 \\
\hline 0.159 & 0 & 4.73037 \\
\hline
\end{tabular}

\begin{tabular}{|c|c|c|}
\hline 0.1592 & 0 & 4.40505 \\
\hline 0.1593 & 0 & 3.97154 \\
\hline 0.1595 & 0 & 3.50858 \\
\hline 0.1597 & 0 & 3.09689 \\
\hline 0.1598 & 0 & 2.73533 \\
\hline 0.16 & 0 & 2.42161 \\
\hline 0.1602 & 0 & 2.15373 \\
\hline 0.1603 & 0 & 1.92485 \\
\hline 0.1605 & 0 & 1.72786 \\
\hline 0.1607 & 0 & 1.55718 \\
\hline 0.1608 & 0 & 1.40925 \\
\hline 0.161 & 0 & 1.28412 \\
\hline 0.1612 & 0 & 1.17754 \\
\hline 0.1613 & 0 & 1.08499 \\
\hline 0.1615 & 0 & 1.00282 \\
\hline 0.1617 & 0 & 0.930724 \\
\hline 0.1618 & 0 & 0.870451 \\
\hline 0.162 & 0 & 0.819562 \\
\hline 0.1622 & 0 & 0.774777 \\
\hline 0.1623 & 0 & 0.73373 \\
\hline 0.1625 & 0 & 0.696574 \\
\hline 0.1627 & 0 & 0.666285 \\
\hline 0.1628 & 0 & 0.641337 \\
\hline 0.163 & 0 & 0.61883 \\
\hline 0.1632 & 0 & 0.596933 \\
\hline 0.1633 & 0 & 0.57641 \\
\hline 0.1635 & 0 & 0.560464 \\
\hline 0.1637 & 0 & 0.547646 \\
\hline 0.1638 & 0 & 0.535897 \\
\hline 0.164 & 0 & 0.523079 \\
\hline 0.1642 & 0 & 0.510567 \\
\hline 0.1643 & 0 & 0.501793 \\
\hline 0.1645 & 0 & 0.495155 \\
\hline 0.1647 & 0 & 0.488823 \\
\hline 0.1648 & 0 & 0.480812 \\
\hline 0.165 & 0 & 0.472267 \\
\hline 0.1652 & 0 & 0.467079 \\
\hline 0.1653 & 0 & 0.463722 \\
\hline 0.1655 & 0 & 0.460212 \\
\hline 0.1657 & 0 & 0.455177 \\
\hline 0.1658 & 0 & 0.44892 \\
\hline
\end{tabular}




\begin{tabular}{|c|c|c|}
\hline 0.166 & 0 & 0.445869 \\
\hline 0.1662 & 0 & 0.444419 \\
\hline 0.1663 & 0 & 0.442359 \\
\hline 0.1665 & 0 & 0.438849 \\
\hline 0.1667 & 0 & 0.433585 \\
\hline 0.1668 & 0 & 0.431449 \\
\hline 0.167 & 0 & 0.431144 \\
\hline 0.1672 & 0 & 0.429999 \\
\hline 0.1673 & 0 & 0.427176 \\
\hline 0.1675 & 0 & 0.422904 \\
\hline 0.1677 & 0 & 0.421225 \\
\hline 0.1678 & 0 & 0.421149 \\
\hline 0.168 & 0 & 0.420539 \\
\hline 0.1682 & 0 & 0.418326 \\
\hline 0.1683 & 0 & 0.41474 \\
\hline 0.1685 & 0 & 0.413901 \\
\hline 0.1687 & 0 & 0.414588 \\
\hline 0.1688 & 0 & 0.414511 \\
\hline 0.169 & 0 & 0.412375 \\
\hline 0.1692 & 0 & 0.408942 \\
\hline 0.1693 & 0 & 0.408026 \\
\hline 0.1695 & 0 & 0.408789 \\
\hline 0.1697 & 0 & 0.409018 \\
\hline 0.1698 & 0 & 0.407263 \\
\hline 0.17 & 0 & 0.404059 \\
\hline 0.1702 & 0 & 0.403449 \\
\hline 0.1703 & 0 & 0.404517 \\
\hline 0.1705 & 0 & 0.405127 \\
\hline 0.1707 & 0 & 0.403601 \\
\hline 0.1708 & 0 & 0.400549 \\
\hline 0.171 & 0 & 0.400015 \\
\hline 0.1712 & 0 & 0.400931 \\
\hline 0.1713 & 0 & 0.40177 \\
\hline 0.1715 & 0 & 0.400549 \\
\hline 0.1717 & 0 & 0.39765 \\
\hline 0.1718 & 0 & 0.397345 \\
\hline 0.172 & 0 & 0.398489 \\
\hline 0.1722 & 0 & 0.3991 \\
\hline 0.1723 & 0 & 0.397955 \\
\hline 0.1725 & 0 & 0.395132 \\
\hline 0.1727 & 0 & 0.394903 \\
\hline
\end{tabular}

\begin{tabular}{|c|c|c|}
\hline 0.1728 & 0 & 0.396277 \\
\hline 0.173 & 0 & 0.397192 \\
\hline 0.1732 & 0 & 0.396353 \\
\hline 0.1733 & 0 & 0.39353 \\
\hline 0.1735 & 0 & 0.393301 \\
\hline 0.1737 & 0 & 0.394827 \\
\hline 0.1738 & 0 & 0.39559 \\
\hline 0.174 & 0 & 0.394751 \\
\hline 0.1742 & 0 & 0.392157 \\
\hline 0.1743 & 0 & 0.391775 \\
\hline 0.1745 & 0 & 0.393225 \\
\hline 0.1747 & 0 & 0.394064 \\
\hline 0.1748 & 0 & 0.392691 \\
\hline 0.175 & 0 & 0.390021 \\
\hline 0.1752 & 0 & 0.389563 \\
\hline 0.1753 & 0 & 0.390707 \\
\hline 0.1755 & 0 & 0.391852 \\
\hline 0.1757 & 0 & 0.390707 \\
\hline 0.1758 & 0 & 0.387961 \\
\hline 0.176 & 0 & 0.387884 \\
\hline 0.1762 & 0 & 0.38941 \\
\hline 0.1763 & 0 & 0.390707 \\
\hline 0.1765 & 0 & 0.389792 \\
\hline 0.1767 & 0 & 0.387121 \\
\hline 0.1768 & 0 & 0.386816 \\
\hline 0.177 & 0 & 0.388037 \\
\hline 0.1772 & 0 & 0.389105 \\
\hline 0.1773 & 0 & 0.388342 \\
\hline 0.1775 & 0 & 0.385748 \\
\hline 0.1777 & 0 & 0.385367 \\
\hline 0.1778 & 0 & 0.386816 \\
\hline 0.178 & 0 & 0.387961 \\
\hline 0.1782 & 0 & 0.387045 \\
\hline 0.1783 & 0 & 0.384451 \\
\hline 0.1785 & 0 & 0.384375 \\
\hline 0.1787 & 0 & 0.385824 \\
\hline 0.1788 & 0 & 0.387121 \\
\hline 0.179 & 0 & 0.386358 \\
\hline 0.1792 & 0 & 0.383688 \\
\hline 0.1793 & 0 & 0.383459 \\
\hline 0.1795 & 0 & 0.384985 \\
\hline
\end{tabular}




\begin{tabular}{|r|r|r|}
\hline 0.1797 & 0 & 0.386282 \\
\hline 0.1798 & 0 & 0.385443 \\
\hline 0.18 & 0 & 0.382849 \\
\hline 0.1802 & 0 & 0.382467 \\
\hline 0.1803 & 0 & 0.384146 \\
\hline 0.1805 & 0 & 0.385519 \\
\hline 0.1807 & 0 & 0.384833 \\
\hline 0.1808 & 0 & 0.382315 \\
\hline 0.181 & 0 & 0.381857 \\
\hline 0.1812 & 0 & 0.383688 \\
\hline 0.1813 & 0 & 0.384909 \\
\hline 0.1815 & 0 & 0.384451 \\
\hline
\end{tabular}

\begin{tabular}{|r|r|r|}
\hline 0.1817 & 0 & 0.382086 \\
\hline 0.1818 & 0 & 0.381857 \\
\hline 0.182 & 0 & 0.383536 \\
\hline 0.1822 & 0 & 0.384909 \\
\hline 0.1823 & 0 & 0.384222 \\
\hline 0.1825 & 0 & 0.381857 \\
\hline 0.1827 & 0 & 0.381476 \\
\hline 0.1828 & 0 & 0.383078 \\
\hline 0.183 & 0 & 0.384527 \\
\hline 0.1832 & 0 & 0.383917 \\
\hline 0.1833 & 0 & 0.381704 \\
\hline
\end{tabular}




\section{Appendix G}

\section{Insertion and Extraction Test Photographs}




\section{Appendix G Insertion and Extraction Test Photographs}

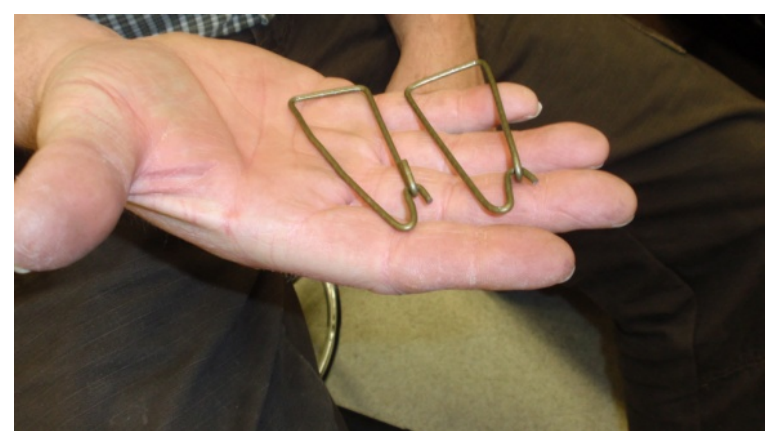

Bales for lifting

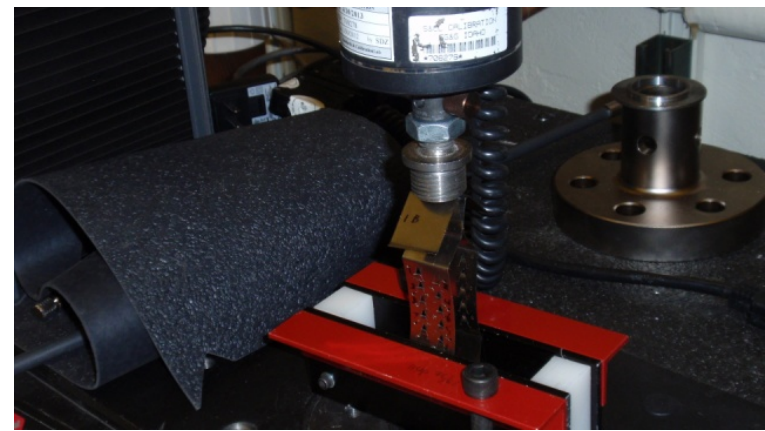

Pushing in clip with test ram

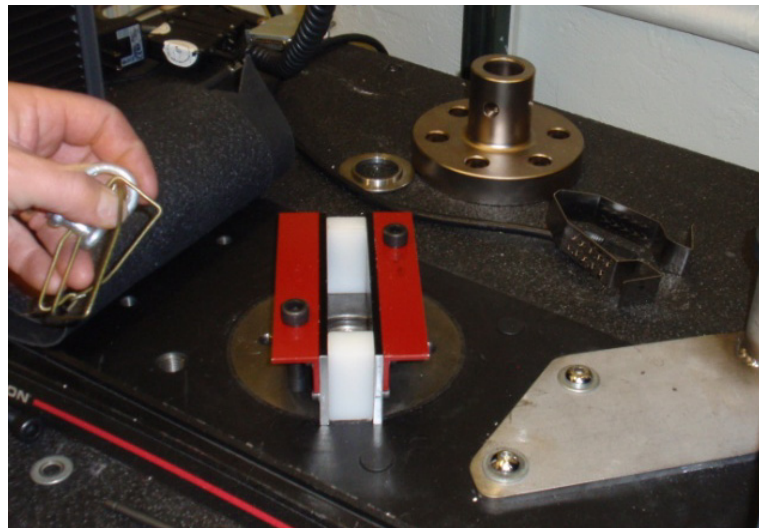

Bolting down frame to test system

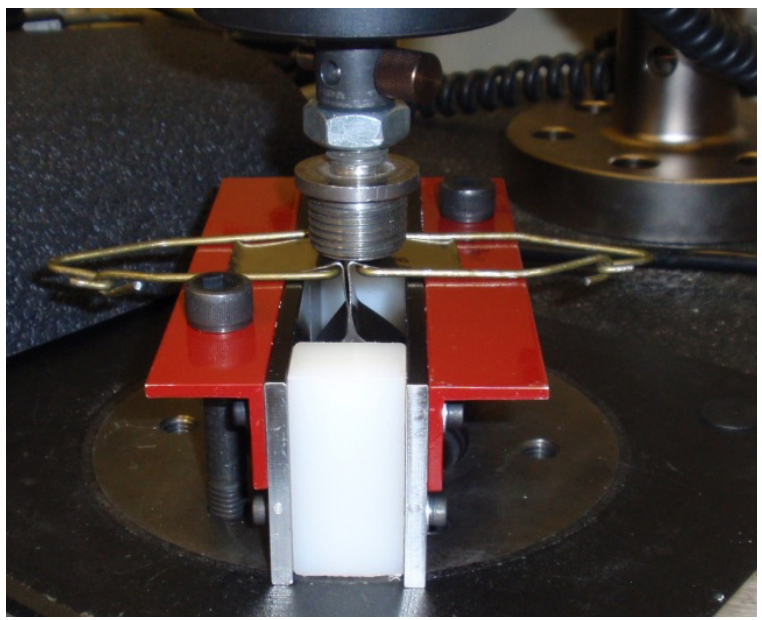

Ram bottoming out on frame with bales in place 


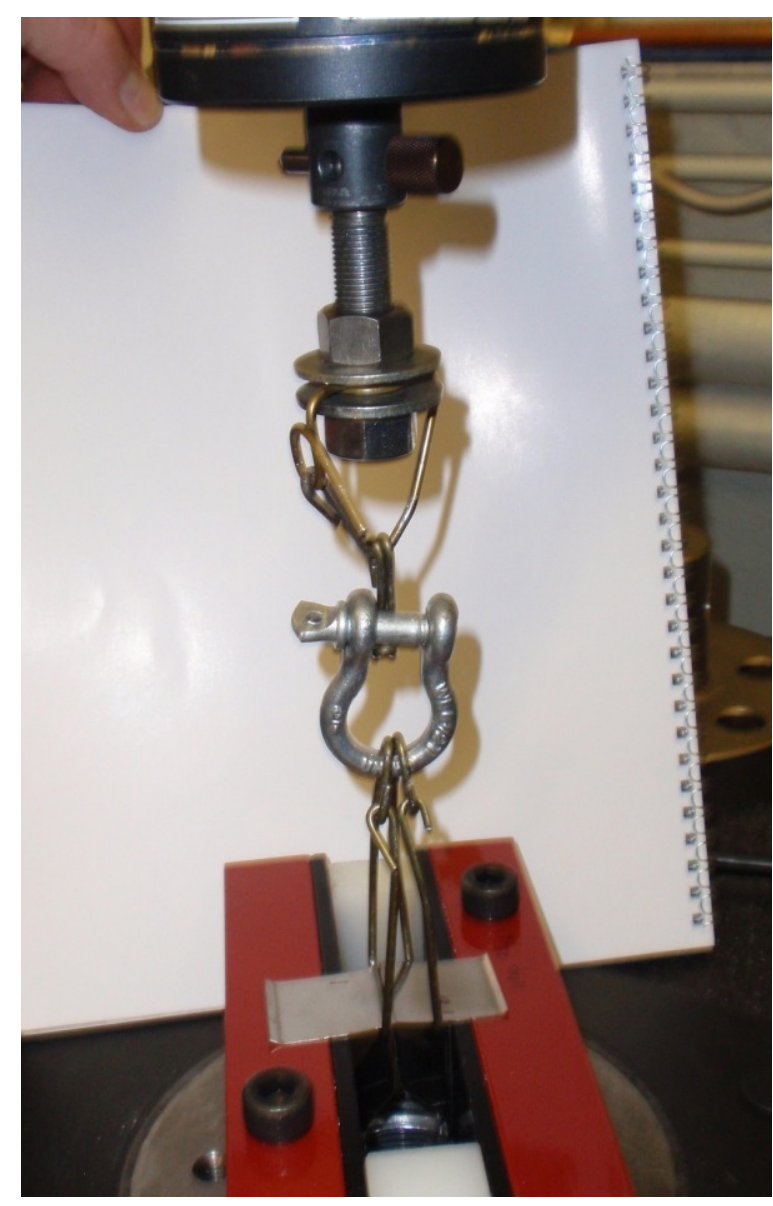

Lifting fixture

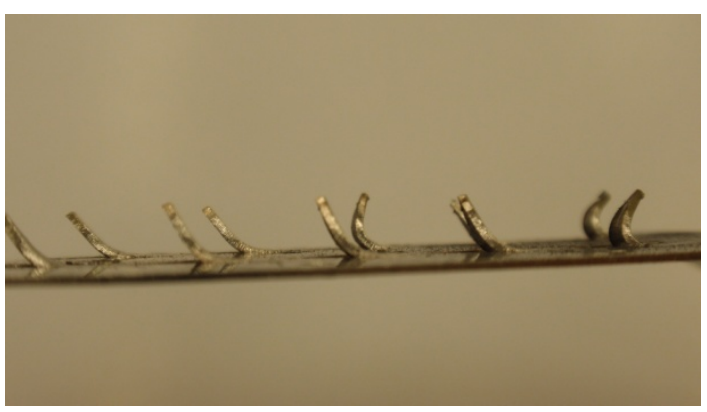

Clip teeth following extraction

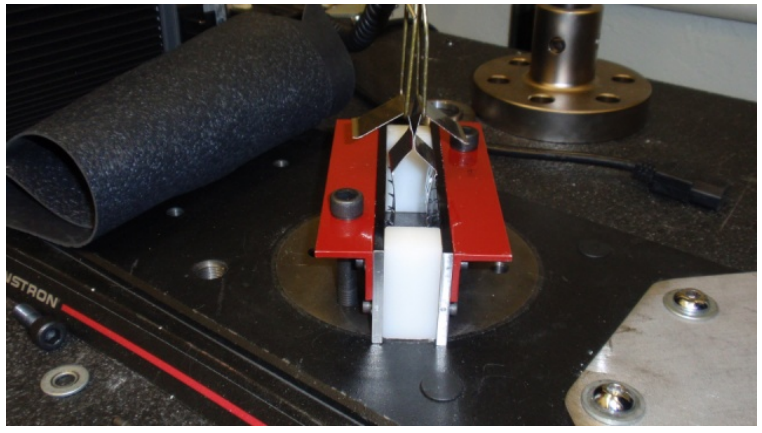

Pulling out the clip

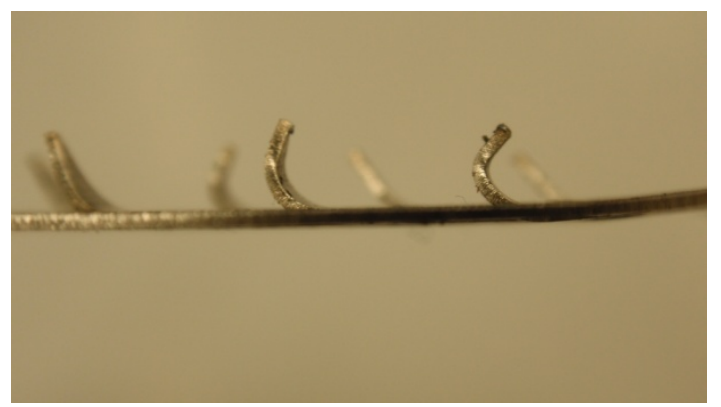


This page intentionally left blank. 


\section{Appendix $\mathrm{H}$}

\section{Teeth Measurements}




\section{Appendix $\mathrm{H}$ \\ Teeth Measurements}

\begin{tabular}{|c|c|c|c|c|c|c|c|c|c|c|}
\hline 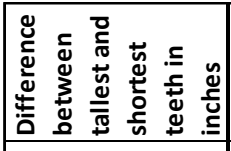 & & $\mid \begin{array}{l}0 \\
0 \\
0 \\
0 \\
0\end{array}$ & & & 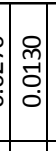 & & & & & \\
\hline 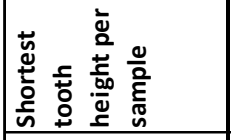 & & 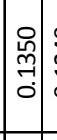 & 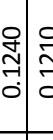 & & : & & & & & \\
\hline 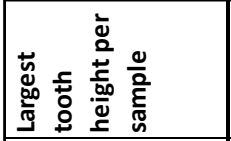 & & $\mid \begin{array}{c}\text { n̂. } \\
\hat{n} \\
0 \\
0\end{array}$ & 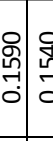 & & 㝵 & & & & & \\
\hline 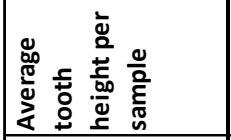 & & $\mid$\begin{tabular}{c}
$\mathscr{2}$ \\
\multirow{2}{1}{} \\
\hdashline \\
0
\end{tabular} & 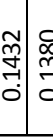 & & & $\begin{array}{l}\hat{0} \\
ٌ \\
0\end{array}$ & & & & \\
\hline 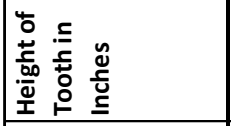 & 요 & \begin{tabular}{|c|c}
0 \\
0 \\
0 \\
0
\end{tabular} & 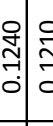 & ât. & $\mid$ & $\begin{array}{l}0 \\
9 \\
7 \\
0 \\
0\end{array}$ & 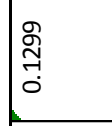 & 岂 & 兽 & $\begin{array}{l}n \\
\stackrel{2}{a} \\
0 \\
0\end{array}$ \\
\hline 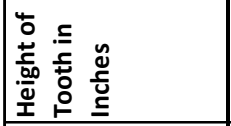 & a & $\begin{array}{l}0 \\
0 \\
0 \\
0\end{array}$ & & & $\stackrel{0}{\substack{0 \\
m \\
\hdashline \\
0}}$ & & 品 & 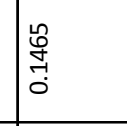 & 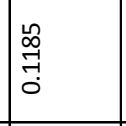 & 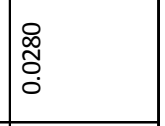 \\
\hline 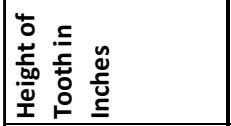 & $\infty$ & $\begin{array}{l}0 \\
0 \\
9 \\
0\end{array} \mid$ & 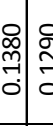 & & 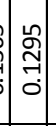 & 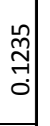 & 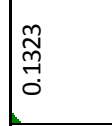 & $\begin{array}{l}R \\
m \\
\stackrel{9}{0} \\
0\end{array}$ & 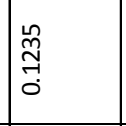 & $\begin{array}{l}n \\
\tilde{m} \\
\vdots \\
0 \\
0\end{array}$ \\
\hline 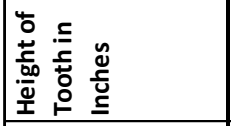 & N & 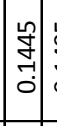 & 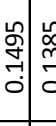 & 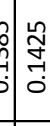 & 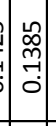 & 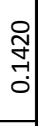 & 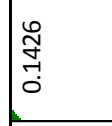 & $\begin{array}{l}\text { 将 } \\
\text { A } \\
0\end{array}$ & $\mid$\begin{tabular}{l}
$\infty$ \\
$\dddot{\infty}$ \\
\hdashline \\
0 \\
0
\end{tabular} & $\begin{array}{l}0 \\
\text { 곰 } \\
0\end{array}$ \\
\hline 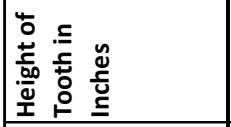 & 0 & 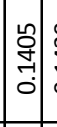 & & & : & م્ & $\mid$\begin{tabular}{l}
$\Omega$ \\
0 \\
0 \\
\hdashline \\
0
\end{tabular} & 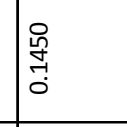 & 角 & 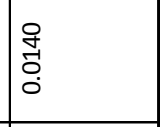 \\
\hline 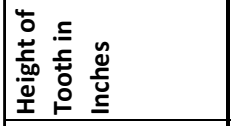 & in & $\mid \begin{array}{c}\stackrel{n}{2} \\
\\
0\end{array}$ & & بـ & $\mid$ & 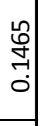 & 孛 & 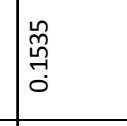 & 崇 & 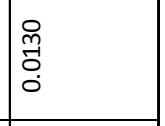 \\
\hline 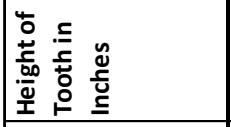 & $\sigma$ & 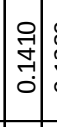 & 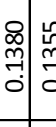 & 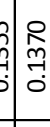 & $\stackrel{\substack{0 \\
\hdashline \\
\hdashline \\
\hdashline}}{0}$ & 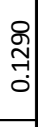 & 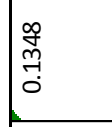 & 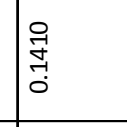 & & $\begin{array}{l}0 \\
\stackrel{m}{m} \\
0 \\
0 \\
0\end{array}$ \\
\hline 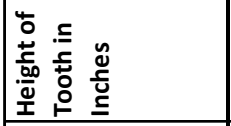 & $m$ & 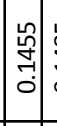 & & & 足 & 号 & 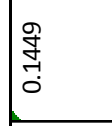 & 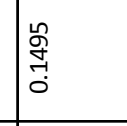 & \begin{tabular}{l} 
恧 \\
\hdashline \\
0
\end{tabular} & $\begin{array}{l}q \\
\stackrel{9}{9} \\
0 \\
0\end{array}$ \\
\hline 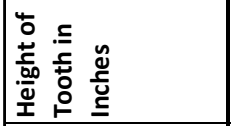 & N & 岁 & & & $\mid$ & 总 & 竎 & 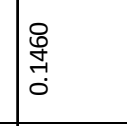 & 兽 & $\begin{array}{l}0 \\
0 \\
0 \\
0 \\
0\end{array}$ \\
\hline 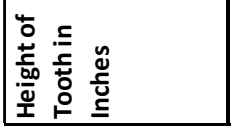 & -1 & 望 & 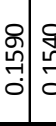 & & $\begin{array}{l}0 \\
\vdots \\
\vdots \\
\vdots \\
\vdots \\
0\end{array}$ & & 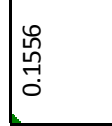 & $\begin{array}{l}\text { 怘 } \\
\stackrel{0}{0} \\
0\end{array}$ & 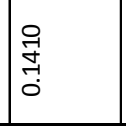 & 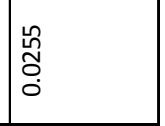 \\
\hline 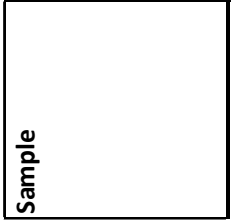 & 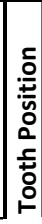 & & & & & $\stackrel{\infty}{m}$ & 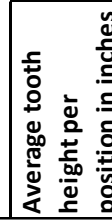 & 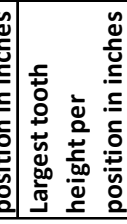 & 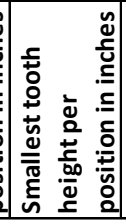 & 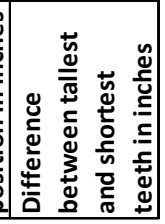 \\
\hline
\end{tabular}

